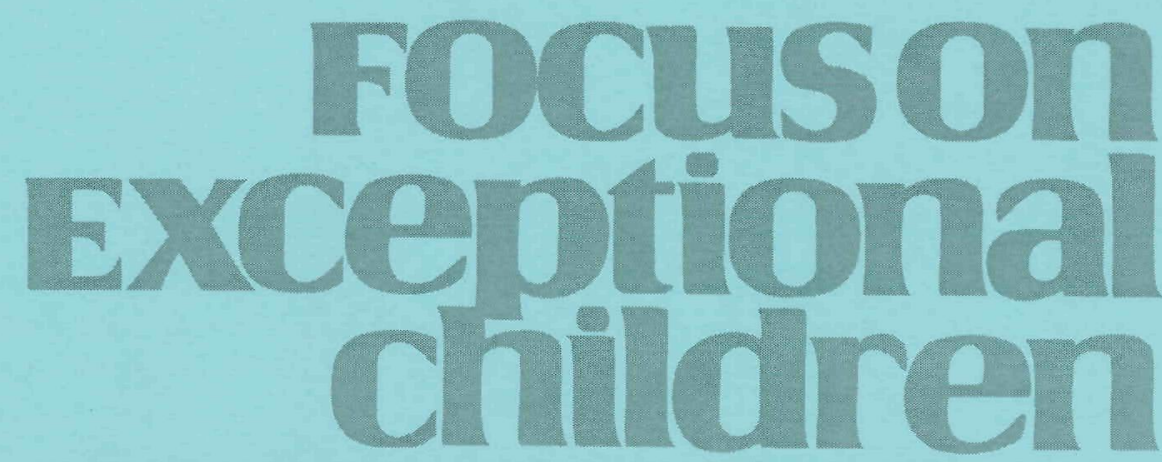

\title{
The Response to Intervention (RTI) Approach in Early Childhood
}

\author{
Charles R. Greenwood, Tracy Bradfield, Ruth Kaminski, Maura Linas, \\ Judith J. Carta, and Donna Nylander
}

Seeking to achieve greater effectiveness in educating the nation's youth, the Response to Intervention (RTI) approach is increasingly being implemented in US schools (Berkeley, Bender, Peaster, \& Saunders, 2009; Walker \& Shinn, 2010). The approach is a paradigm shift in $\mathrm{K}-12$ education that is affecting early education, early intervention, and early childhood special education as well. The shift moves practice away from the traditional model of waiting for students to qualify for special education before serving them to one of intervening immediately to prevent developmental delays and challenges from becoming disabilities. Supporting implementation of RTI are favorable policies in the No Child Left Behind Act (NCLB, 2001) and the Individuals with Disabilities Education Improvement Act (IDEA, 2004) that have put the spotlight on improving students' results through early and sustained use of evidence-based practice. While not specifically addressed in early childhood special education policy, RTI is supported by federal and state accountability policies requiring annual reporting of individual child progress and an expectation of improving results for children served (Head Start for School Readiness Act, 2007; US Department of Education [USDE], 2006).

The policies and reports of professional organizations and advocacy groups like the National Association of State Directors of Special Education, National Association of School Psychologists, and the National Center for Learning Disabilities (NCLD) also support the RTI model. These organizations, among others, (e.g., National Association of State Special Education Directors, 2008; Shinn \& Walker, 2010; Thomas \& Grimes, 2008) embrace RTI as a science-based practice and have made RTI knowledge and practice part of their professional expectations and advocacy. The Council for Exceptional Children has a position statement on RTI (CEC, 2007), and the Division of Early Childhood (DEC), in conjunction with the National Association of the Education of Young Childhood (NAEYC) and the Head Start Association are currently working on a joint early childhood position statement on RTI.

\footnotetext{
Dr. Greenwood is a professor of applied behavioral science at the University of Kansas. Dr. Bradfield is a research associate with the Center for Early Education and Development at the University of Minnesota. Dr. Kaminski is the director of research and development at the Dynamic Measurement Group, Eugene, OR. Dr. Linas is an assistant research professor at the University of Kansas. Dr. Carta is a professor of special education at the University of Kansas.
} 
RTI is a framework supporting differentiating instructional interventions for individual students based on their demonstrated need (Gersten et al., 2008). RTI uses a unique measurement approach that begins with universal screenings of all children on multiple occasions during the school year. These data are used by educators to identify children who are not making expected rates of short-term progress and who may benefit from more intensive intervention. Identified children are provided additional intervention along with more frequent monitoring of progress and frequent intervention decision making (DEC, 2007; Fuchs \& Fuchs, 2007). Commonly described as Multi-Tier Systems of Support (MTSS), interventions of increasing intensity are used to provide an appropriate intensity of service, one matching a child's demonstrated response to intervention (Greenwood, Carta, et al., 2008; Greenwood, Kratchowill, \& Clements, 2008). The screenings are used to identify the subset of children in a school, program, or classroom falling below a benchmark standard given the general classroom curriculum and instructional strategies. These children are

\section{Focuson
Exceptional children}

ISSN 0015-511X FOCUS ON EXCEPTIONAL CHILDREN (USPS 203-360) is published monthly except June, July, and August as a service to teachers, special educators, curriculum specialists, administrators, and those concerned with the special education of exceptional children. This publication is annotated and indexed by the ERIC Clearinghouse on Handicapped and Gifted Children for publication in the monthly Current Index to Journals in Education (CIJE) and the quarterly index, Exceptional Children Education Resources (ECER). The full text of Focus on Exceptional Children is also available in the electronic versions of the Education Index. It is also available in microfilm from Serials Acquisitions, National Archive Publishing Company, P.O. Box 998, Ann Arbor, MI 48106-0998. Subscription rates: individual, $\$ 50$ per year; institutions, \$68 per year. Copyright (C) 2011, Love Publishing Company. All rights reserved. Reproduction in whole or part without written permission is prohibited. Printed in the United States of America. Periodical postage is paid at Denver, Colorado. POSTMASTER: Send address changes to:

$$
\begin{gathered}
\text { Love Publishing Company } \\
\text { Executive and Editorial Office } \\
\text { P.O. Box } 22353 \\
\text { Denver, Colorado } 80222 \\
\text { Telephone (303) 221-7333 }
\end{gathered}
$$

\section{CONSULTING EDITORS} Steve Graham
Vanderbilt University University of Nebraska-Lincoln

Eva Horn

University of Kansas
Carrie E. Watterson Senior Editor
Stanley F. Love Publisher provided more intensive services (Tier 2) and their skill growth monitored more frequently. If children continue to demonstrate lack of progress, the decision is made to provide more intensive services (Tier 3). Alternately, if sufficient progress is evident, the decision is made that the child no longer needs the intensive intervention and is moved back to less intensive services (Tier 1 ).

Compared to traditional special education models, MTSS services in RTI are provided earlier. Children receiving more intensive services may or may not have an Individual Family Service Plan (IFSP) or Individual Education Plan (IEP), and movement between levels of service is dynamic, based on demonstrated progress within a school year. Additionally, the locally collected progress data are used as basis for making annual program improvements such as a change in curriculum, more professional development in support of the RTI approach, or both (Kratchowill, Clements, \& Kalymon, 2007).

\section{WHAT ARE THE POTENTIAL BENEFITS?}

A rising proportion of children enter early education programs with limited exposure to early literacy experiences at home or in childcare, putting them at risk for not achieving expected language, literacy, and social-emotional outcomes in preschool (Shonkoff \& Phillips, 2000; Zill \& Resnick, 2006). A large proportion of these students become struggling readers (Chard \& Kameenui, 2000), on the way to needing special education services for reading disabilities (Marston, 2005). Yet, we know that special education service rates are malleable to some extent. For example, Belfield (2005) reported that attending preschool was associated with a $12 \%$ fall in the rate of special education identification. Special education service rates for learning disabilities were $38 \%$ lower for children attending preschool (Conyers, Reynolds, \& Ou, 2003). We also know that children who have problems learning to read are at greater risk for experiencing behavior problems in their elementary years (McIntosh, Horner, Chard, Boland, \& Good, 2006).

The potential benefit of RTI in early childhood is the ability to provide key social-emotional and early literacy experiences for those children who lack these experiences and the key skills to prevent the need for special education services for language, literacy, and behavior disorders, particularly for this population of children with experiential deficits. For children with disabilities, the benefit of RTI is the potential for improved outcomes resulting from its ability to provide seamless interventions for individual children that result in progress (Fletcher \& Vaughn, 2009) and less regression and loss of function over time that might otherwise be expected to occur without these early and intensive services. The benefit of RTI in early childhood at the child 
and program levels is as an approach to achieving overall greater effectiveness (Greenwood, 2008).

The RTI approach in early childhood programs is emerging (Buysee \& Peisner-Feinberg, 2009; Fox, Carta, Strain, Dunlap, \& Hemmeter, 2010; Linas, Greenwood, \& Carta, 2009), and its designers must take into account the unique challenges present in the early childhood system, not the least of which are the lack of a universal access to early education and the lack of a unified early childhood education system (Greenwood, 2009). The purpose of this article is to survey the current status of RTI implementation in early childhood settings serving children from birth to age 5 prior to kindergarten. The goal is not an exhaustive review but rather examination of implementation as reported by statelevel directors and coordinators. We also point to advances in RTI models, research, practices, and program examples in early childhood.

Because some readers may be unfamiliar with the unique features of early childhood programs, we set the stage by describing (a) the context for RTI in the early education system and (b) the skills that research indicates early education must help children master to be ready for kindergarten. Afterwards, we examine aspects of early childhood that are a fit to RTI along with challenges and myths that may be barriers to be overcome in future research and practice. We report current areas of accomplishment as well as ongoing research and development, and we suggest policy needed in support of early childhood RTI implementation. We conclude with implications for research, policy, and practices.

\section{WHAT IS THE SYSTEM CONTEXT FOR EARLY CHILDHOOD RTI?}

Universal access to early education in the United States is yet to be achieved, even though it is well known that the early childhood years are the last untapped opportunity to vastly improve the national education product (Heckman, 2006). This said, the implication is that many children will not receive formal educational experiences prior to kindergarten and will not be ready to succeed in elementary school. Instead of a universal system of public early education for all, as is the case with $\mathrm{K}-12$ education, early childhood education in the US is a collection of programs with some supported by federal policy, some by state policy, and others by grassroots community activities (Bagnato, 2007). As a result, programs available to families vary widely within localities and across states. The most widespread and systematic are the federal programs serving children in poverty (i.e., Early Head Start, Head Start) and children at risk for developmental delay and disabilities (i.e., eligible for early intervention under IDEA, Part C, and early childhood special education [IDEA, Part B-619 preschool] programs funded by IDEA). Some states provide additional funds in support of these programs so that more children may be served. Additionally, federally supported Title 1 programs also provide preschool services for children qualifying because of low family income. State-funded preschool (Pre-K) programs linked to area $\mathrm{K}-12$ schools are supported in many states but not all (Barnett, Epstein, Friedman, Sansanelli, \& Hustedt, 2009). Remaining are community-based preschool programs including parochial and private pay.

In all, each has separate policies, selection criterion, funding sources, goals, staff, and approaches to education. For example, the time available for children to attend their preschool program varies widely from half to whole day, and often children attend fewer than 5 days per week. Because RTI is an approach dedicated to serving all children in a system, designers of RTI programs in early childhood have the extra challenge of dealing with system cross-coordination/ collaboration issues to a much greater extent than $\mathrm{K}-12$.

Unlike $\mathrm{K}-12$ education, where consensus goals are to teach academic content, much less agreement exists in early childhood programs on both what to teach and how to teach. At the level of goals, measures, and instruction, for example, most preschool programs are places where children are provided opportunities to engage in play that is believed to support their growth and development in traditional developmental domains of language, cognition, social-emotional, and gross and fine motor. However, many continue to be less willing to embrace the teaching and assessment of early academic content, including early literacy skills. Of those that do focus on early literacy and other academic content domains (e.g., math, science), many use curricula that do not have a clear evidence base (Mashburn, 2008). While the NAEYC supports intentional teaching of young children as a part of the most recent revision of the association's Developmental Appropriate Practices (NAEYC, 2011), some sectors of early childhood continue to view explicit teaching of skills as not developmentally appropriate (see Glossary). Finally, the vast majority of early education programs are just beginning to look at issues of aligning early learning standards with those of $\mathrm{K}-12$ schooling.

Collectively, these system issues present challenges to RTI designers in terms of scope, services, time, and blending funding within and across programs providing services to all children who need support (Lesko, Houle, \& Tschantz, 2010). These issues present challenges to adoption of the RTI approach at the level of administration and staff who may or may not embrace the RTI approach to services. Given this context, designers of early childhood RTI programs will not simply be able to fit elementary RTI models to early childhood settings (as discussed later in the article). Rather, they will need to design RTI models that address the challenges inherent to early childhood settings. 


\section{What Outcomes Need to Be Taught and Learned in Preschool?}

For many children, preschool programs are their first formal educational experiences. Children who have not had the opportunity to learn from key early experiences prior to kindergarten face significant challenges learning to read (Torgesen, 2002; Whitehurst \& Lonigan, 1998, 2001). Whereas it used to held that reading instruction began when children started school, findings from a wide body of empirical evidence over the past few decades indicate that the precursors to the reading skills taught in the early school years begin developing prior to formal schooling. The preliterate skills needed to be successful in learning to read and that are developmental precursors to conventional reading and writing skills have been reported to account for significant and unique variance in the prediction of reading achievement and are termed emergent literacy skills (Whitehurst \& Lonigan, 2001).

A focus on emergent literacy in Pre-K, for example, does not mean simply a downward extension of the skills formerly taught in kindergarten and first grade. The skills children need to learn and that should be taught in preschool are different from, albeit aligned with, those taught in $\mathrm{K}-12$ and supported by research evidence. These skills also must be aligned with state standards. Thus, it is important that the teaching of emergent literacy skills take place in preschool in order that adequate early literacy experiences before kindergarten are provided. These experiences enable children to acquire knowledge of two interdependent domains of information needed to learn to read. First, children need sources of information that will directly support their understanding of the meaning of print in school. These include vocabulary knowledge, oral language skills, language comprehension, and conceptual knowledge leading to reading comprehension (Biemiller, 2006; Scarborough, 1998; Tunmer, Herriman, \& Nesdale, 1988). Children also need to be able to translate print into sounds and sounds into print (Treiman, Tincoff, \& Richmond-Welty, 1997). Some of these early skills supported by research include oral language, phonemic awareness, familiarity with the alphabet, and print awareness (Badian, 2000; Burgess \& Lonigan, 1998; Juel, 2006; Wagner et al., 1997).

In kindergarten and prior to third grade, children should be learning phonological awareness, phonemic decoding skills, an increasing lexicon of words (vocabulary) identifiable at a single glance (fluency), and comprehension. Students arriving in third grade with these skills will be able to read third-grade text accurately and fluently with variable levels of understanding (Moats, 1999; National Reading Panel, 2000). Reading skill components that differentiate reading achievement after third grade include continued growth in the lexicon of words, acquisition of the complex vocabulary that appears primarily in written text, acquisition of strategies for processing different types of text (e.g., narrative, expository), growth in conceptual and background knowledge, and growth in reasoning and inferential skills. The most important outcome of elementary reading instruction is comprehension of written material (Block, Gambrell, \& Presley, 2002; Torgesen, 1998, 2002). Thus, learning language and early literacy skills before kindergarten is a huge advantage.

With respect to socio-emotional skills, evidence indicates that learning language and literacy skills in preschool is moderated by personal or social competencies. These competencies include regulation of attention, engagement, and ability to follow classroom directions. Evidence indicates that regulation of attention and engagement play key roles in children's classroom learning and that there is an overlap between attention and behavior problems and reading disabilities (Lonigan, Anthony, Bloomfield, Dyer, \& Samwel, 1999).

Young children with poor attention skills have less developed emergent literacy skills (i.e., print knowledge, oral language, phonological memory). The ability to follow directions and sustain attention is necessary for young children to remain actively engaged when learning (Kamps, Greenwood, Arreaga-Mayer, Abbott, \& Utley, 2002; Torgesen, 2002). Research reports that child engagement in classroom activities is one of the best single behavioral correlates of developmental status of children (Ridley, McWilliam, \& Oates, 2000b) and that engagement is altered by specific features of the classroom environment with particular sensitivity to changes in activity structure, materials, teacher behavior, and group size (Carta, Greenwood, \& Robinson, 1987; Ridley et al., 2000a). Increased engagement has been reported to be related to decreased behavior problems and improved phonological awareness skills (Lane, O'Shaughnessy, Lambros, Gresham, \& Bebbe-Frankenberger, 2001; Torgesen et al., 1999).

Children further need to learn to function independently in the classroom (Carta, Sainato, \& Greenwood, 1988). When surveyed, kindergarten teachers' expectations for the independence skills most needed by children entering kindergarten were the ability to complete work independently; participate in groups; and make timely, independent transitions between activities. Carta et al. (1988) reported that children taught these skills in preschool had better outcomes in kindergarten and first grade with respect to cognitive outcomes and need for special education services.

Social competencies also play key roles in children's classroom learning (Sainato \& Carta, 1992). Children's social competencies and relationships with peers have an effect on whether their transition to preschool and other schooling experiences will be successful (Huffman, Mehlinger, \& 
Kerivan, 2000). Children's classroom friendships relate to adjustment to school, need for mental health support, and overall school performance (Ladd, Kochenderfer, \& Coleman, 1996). Children with language and reading disabilities are at high risk for impaired social interactional skills and opportunities, social withdrawal, and peer rejection (Gertner, Rice, \& Hadley, 1994; Lonigan et al., 1999). Guralnick, Connor, Hammond, Gottman, and Kinnish (1996) reported that children with developmental disabilities in Head Start were at risk because they receive fewer opportunities for interactions with their peers, are less successful in their social bids to peers, and develop fewer friendships. Social and behavioral difficulties not only impede later school outcomes but also negatively affect children's interactions with their teachers and peers, leading to social withdrawal and peer rejection (Gertner et al., 1994).

The domains of oral language, early literacy, and personal and social competencies compliment, support, constrain, and reflect one another. Children's emergent literacy skills are advanced through their conversational interactions with adults and social interactions with peers. When problems with these interactions arise, naturally supportive processes instead become processes that impede or constrain one another. For example, the relationship between delayed reading and behavior problems is well established, and mechanisms by which falling behind in reading leads to behavior problems and behavior problems lead to delays in learning to read are widely accepted. Similarly, the lack of social competency often leads to behavior problems that interrupt attention and engagement in classroom learning activities, leading to delays in learning to read. The inability to communicate interrupts the learning of phonological skills and new social competencies, thereby accelerating behavior problems and delaying school readiness and learning to read (Webster-Stratton, 1997).

\section{HOW WELL DOES RTI FIT INTO EARLY CHILDHOOD?}

Readers interested in RTI but less familiar with early childhood will be glad to know that early childhood brings unique strengths on which RTI can build. Early childhood programs are already firmly behind the RTI ideas of prevention and early intervention in concept, research, practice, and policy. Early childhood as reflected in its professional organizations and published literature is supported by knowledge that learning begins before birth and that after birth the child's family members are its most important teachers. Quality early environments can protect against the negative impact of depriving environments on social, language, and cognitive outcomes (Sameroff \& Fiese, 1990; Shonkoff \& Phillips, 2000). "Recent research in psychology and cognition demonstrates how vitally important the early preschool years are for skill formation.... Early learning begets later learning and early success breeds later success" (Heckman, 2000, p. 3).

Some sectors of early childhood have embraced the idea of monitoring the progress of individual children as part of providing quality early intervention. This is particularly evident in the context of the IFSP for infants and toddlers and the IEP for preschool children receiving special education services. Service providers must report measurable progress on children's intervention goals as is the case in $\mathrm{K}-12$ special education. Early childhood special education also recognizes that the purpose of assessment to identify children who need additional support, determine what interventions are needed, and monitor and report progress (Bagnato, 2007; DEC, 2007; National Research Council, 2008).

The concept of individualization is embraced and has a long history in the early intervention and early childhood special education sectors of the early childhood system. However, the concept is not yet universally accepted. Some sectors of early childhood are firmly behind the idea of individualizing instruction within the context of the general classroom that is considered recommended practice and supports provision of RTI. Inclusion of young children in the least restrictive environment has a strong basis in early childhood, supported by the major professional organizations, such as NAEYC, DEC, and the National Head Start Association. Individualizing instruction for children with special needs is similarly valued and supported now where it has not always been so (Carta, Schwartz, Atwater, \& McConnell, 1991). Broad support for the concept of intentional teaching, that is, teaching intended to directly teach specific skills, of young children provides a basis for use of MTSS to intensify the instructional experiences of identified children. An additional area of fit between some early childhood sectors and RTI is data-based decision making, which provides a strong basis for RTI. However, there is also variation in these fit concepts across sectors.

In this section, we discussed the early childhood education system, what needs to be taught and the outcomes of early childhood, and RTI's fit to the tenets and practices of early childhood. We now examine implementation issues and the challenges that may need to be addressed in early childhood.

\section{PROGRESS DEVELOPING AND IMPLEMENTING RTI IN EARLY CHILDHOOD}

Results of recent annual surveys of state Pre-K, Part B619, and Head Start coordinators and directors conducted by the Center for Response to Intervention in Early Childhood (CRTIEC) indicated that the field is at the beginning of RTI implementation and is clearly engaged in exploring 
its utility (Linas, Carta, \& Greenwood, 2010; Linas et al., 2009). In 2009, survey data were received representing 40 states, the District of Columbia, three territories, and the Bureau of Indian Affairs. In 2010, survey data were received from respondents in 46 states, the District of Columbia, and two territories. The key question asked of state-level directors and coordinators each year was to report progress implementing RTI using a 6-point differential, ranging from lowest to highest level toward full implementation. The lowest possible rating in both years was No Discussion or Implementation in the state, while the highest rating was Fully Implemented. The interesting trend in RTI implementation from 2009 to 2010 was an increase in ratings indicating greater levels of implementation. For example, the uptick in Professional Development has Begun was from $16 \%$ to 23\%, and for Some Programs have Begun to Implement the increase was from $21 \%$ to $30 \%$. With these increases in implementation levels, decline was seen in the second lowest implementation rating level-Preliminary Discussions are Ongoing. It dropped from $43 \%$ to $24 \%$ in 2010 (see Figure 1). Respondents in only two states reported that they were Fully Implemented in 2010 (4\% of respondents) and very few respondents reported that their states had explicit statewide RTI policies in place guiding RTI in early childhood (4\%). A separate survey of state Head Start directors in 2010 indicated highly similar findings.

\section{EMERGING EARLY CHILDHOOD RTI RESOURCES AND MODELS}

Several sources in the literature are helping translate MTSS intervention models for early childhood implementation. One is the Roadmap to Pre-K RTI (Coleman, Roth, \& West, 2009). Development of the Roadmap was supported by the NCLD and is posted on their RTI Action Network website (http://www.rti network.org/pre-k). The Roadmap presents an introduction to RTI in early childhood and provides several examples of ongoing RTI programs. Two others are specific models: Recognition \& Response (R\&R) and the Teaching Pyramid (TP). R\&R is an RTI instructional model for language and early literacy and numeracy skills, while the TP addresses children's social-emotional development. Both are based on the familiar RTI triangle of hierarchical levels of risk and tiers of support of greater intensities at higher levels (Gersten et al., 2008). The R\&R and TP models uniquely add aspects of early intervention relevant to an RTI approach and to the outcomes of young children they are designed to promote.

\section{National Progress Implementing Preschool RTI}

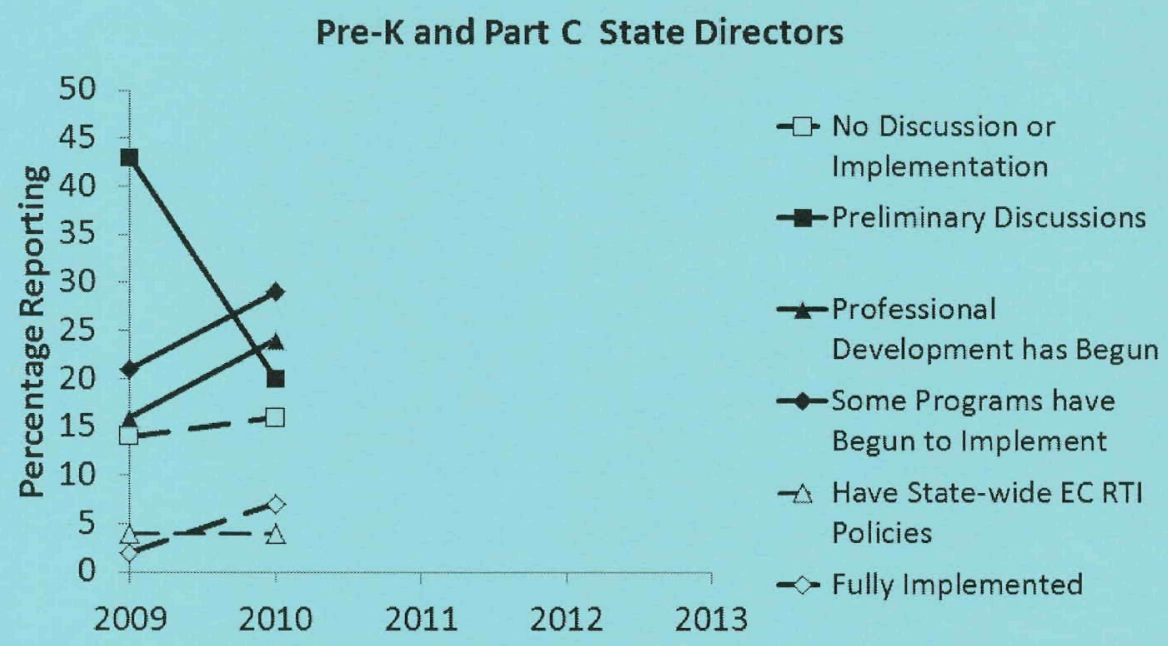

FIGURE 1

Trends in early childhood RTI implementation as reported by state Pre-K and Part B-619 coordinators in 2009 and 2010 


\section{Recognition and Response Model}

R\&R was developed at the Frank Porter Graham Child Development Institute, University of North Carolina in collaboration with the National Center for Learning Disabilities, the National Association for the Education of Young Children, the Communication Consortium Media Center, and key state partners in Arizona, Connecticut, Florida, Maryland, and New Jersey (Buysse \& Peisner-Feinberg, 2009). R\&R is a three-tier model for public Pre-K, child care, Head Start, and preschool instruction providing differential instruction to 3 to 5 year old children based on assessed need. (see Figure 2, right panel)

Guiding RTI principles in the R\&R model are recognizing children not making progress prior to referral, helping teachers support children's academic learning as well as their social-emotional development, and linking RTI and early childhood programming prior to kindergarten with existing programming for school-age children. Four RTI components: (a) screening, assessment, and progress monitoring (recognition), (b) research-based curriculum and instruction for all children and validated interventions for individual children who need additional supports (response), (c) an intervention hierarchy, and (d) a collaborative problemsolving process that involves teachers, specialists, and parents working together are involved. Several studies on the efficacy of R\&R programs are underway (Buysee \& Peisner-Feinberg, 2009).

\section{Teaching Pyramid}

The Teaching Pyramid is a product of the Technical Assistance Center on Social Emotional Intervention for Young Children (TACSE) (Fox et al., 2009; Hemmeter, Ostrosky, \& Fox, 2006). The model describes three tiers of intervention practice: universal promotion for all children, secondary
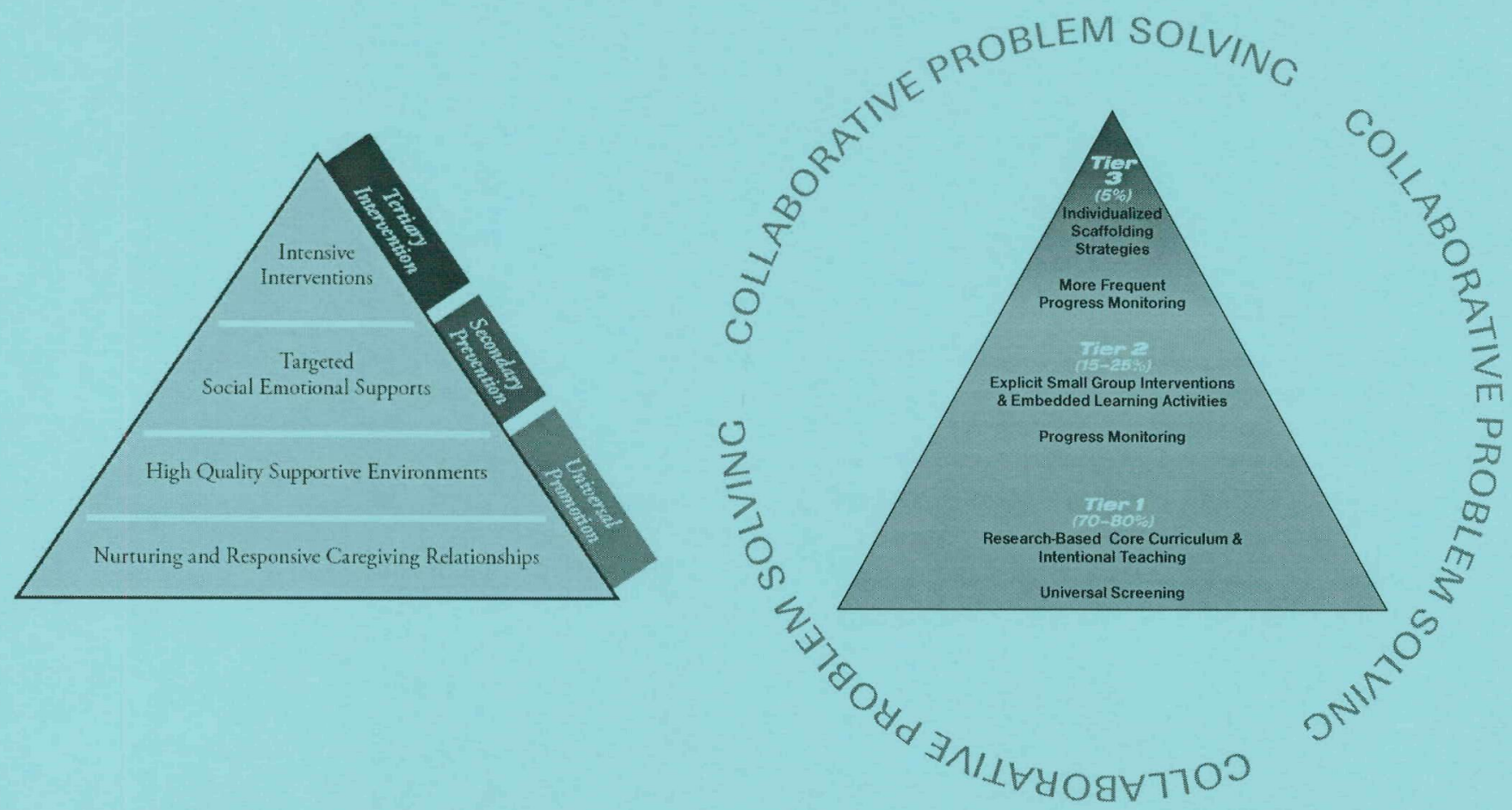

Source: Left panel from "Response to Intervention and the Pyramid Model," by L. Fox, J. J. Carta, P. S. Strain, G. Dunlap, \& M. L. Hemmeter, 2010, Infants and Young Children, 23(1), 3-13. Copyright 2010 by Lise Fox. Reprinted with permission. Right panel from "Recognition \& Response: Response to Intervention for PreK," by V. Buysse \& E. Peisner-Feinberg, 2010, Young Exceptional Children, 13(4), 2-13. Copyright 2009 by Virginia Buysse and Ellen Peisner-Feinberg. Reprinted with permission.

FIGURE 2

Early childhood RTI frameworks. The Teaching Pyramid of RTI for promoting children's social-emotional outcomes (left panel) and Recognition \& Response model for promoting children's early literacy outcomes (right panel) 
preventions to address the intervention needs of children at risk for social-emotional delays, and tertiary interventions needed for children with persistent challenges (see Figure 2, left panel). The pyramid model was initially described as an intervention framework for children 2-5 years old within early childhood settings. However, newer iterations of the model provide guidance for the implementation of the framework with infants, toddlers, and preschoolers and include interventions needed to support children who are typically developing and who have or are at risk for developmental delays or disabilities (Hunter \& Hemmeter, 2009).

Reports on the efficacy of the PM are not yet available. Both models provide early childhood with strong RTI conceptual frameworks needed for creating local program implementations.

The Roadmap and these two models illustrate the translation of RTI to early childhood. These models involve parents in all aspects its procedures, focus on the outcomes of young children supported by evidence, coordinate staff working across sectors of the early childhood system (i.e., between Head Start and Part B-619 services), and provide strong emphasis on the context and culture of the early childhood system. Both models are emerging practices in early childhood; however, with studies underway, relatively little is yet known about their efficacy or effectiveness.

As is often the case with models, the actual component procedures, practices, and tools needed to implement the models in local programs are not necessarily standard elements in these models and are selected for use in the model by implementers. Designers and implementers of RTI models must evaluate, select, and use practices that are most appropriate to their needs. The upshot is that the field is awaiting development and validation of many of these tools. Local practitioners wishing to implement RTI will need to adopt tools that may just be emerging or that they develop themselves. We turn now to a review of some of these tools and work in progress developing them for early childhood RTI applications.

\section{RESEARCH AND DEVELOPMENT OF RTI COMPONENT PRACTICES}

The Center for Response to Intervention in Early Childhood (CRTIEC) is advancing MTSS in early childhood by developing evidence-based Tier 2 and 3 interventions for language and early literacy (2009). They are also developing universal screening and progress monitoring measurement tools aligned with the interventions and the language and early literacy domains. The measures are used for determining which children may benefit from a more intensive level of instruction and for monitoring the progress of children receiving Tier 2 and 3 interventions (see online at www. crtiec.org). CRTIEC received funding in 2008 from the Institute for Education Sciences, National Center for Special Education Research, to do this research and development work and also to provide leadership to the early childhood field in the implementation of RTI. In addition to developing and validating component practices, CRTIEC has completed a descriptive study of preschool core Tier 1 instruction as a means of better understanding the quality of curricula and instructional support for language and early literacy used in preschool Tier 1, including the prevalence of preschool children in programs eligible for Tier 2 and Tier 3 interventions (Carta, Greenwood, \& Atwater, 2010). CRTIEC has also established a national network of interested researchers, practitioners, and policy makers (online at http:// www.crtiec.org/aboutcrtiec/preschoolrti.shtml), and CRTIEC sponsors an annual RTI in Early Childhood Summit meeting focused on what we know and need yet to know about early childhood RTI. Presentations from the 2009 and 2010 Summits can be retrieved online at http://www.crtiec.org/rti_sum mit/index.shtml.

At the heart of both Tier 2 and 3 intervention development lies the use of strong instructional design principles and instructional components known to impact short-term growth and development. Several instructional design principles are unique to the CRTIEC's approach. First, differentiated instruction with a focus on fewer high-priority skills using explicit, systematic instruction in Tiers 2 and 3 is employed. Second, strategies are used that increase children's opportunities to respond and levels of individual child engagement during instruction. Third, individualization and accommodations are used for children with identified disabilities. In addition to effectiveness, a critical aspect of the success of the RTI approach in early childhood must be reasonable cost and feasibility if wide-scale implementation is to be achieved. Part of this equation is instruction that can be implemented well in a system where many available staff members are not certified teachers or have had limited professional preparation and where limited resources are available to implement and manage delivery of differentiated instruction.

Evidence supporting the efficacy of these new Tier 2 and 3 interventions in language and early literacy is being gathered in small-scale studies using single-case designs to demonstrate that the interventions produce measurably superior results for children. Subsequently, the efficacy of the interventions will be advanced further through multisite controlled evaluations and replications. Thus, it will be possible to establish effect sizes and extend the external validity of effectiveness in the near future.

\section{CRTIEC's Tier 2 Language and Early Literacy Interventions}

A Tier 2 instructional intervention package is being developed and validated to provide students with increased 
opportunities to respond through supplemental activities linked to the scope and sequence of a language and early literacy Tier 1 curriculum (Goldstein \& Kaminski, 2010). The Tier 2 intervention materials address the domains of oral language and vocabulary, phonological awareness, print knowledge, and comprehension. The effectiveness of some of the instructional components used in the instructional intervention, such as embedding phonological awareness activities, is based on completed preliminary research (Ziolkowski \& Goldstein, 2008).

To address the issue of limited staff availability for implementing the Tier 2 intervention with groups of students, a listening center approach to providing supplemental activities is being developed. In the listening centers, each child will use an educational media and materials platform, called Skill-Focused Listening Centers (SFLC; Goldstein \& Kaminski, 2010). The platform consists of headphones and an audio track that delivers the weekly lessons (i.e., instructional scripts) that have been prerecorded onto MP3 players. Children also use specially designed books that provide visual and written prompts that are discussed with the student as they listen to the audio track and respond as requested. The system creates a highly responsive context for each child to hear, see, say, receive feedback, and otherwise interact with the content so as to increase their dosage experience with the material and their mastery of the materials. Children are assessed weekly on material taught that week and to be learned next week. An adult, not necessarily a teacher, sets up and monitors the listen center activities with small groups of children (see more online at http:// www.crtiec.org/Research/SkillFocusedListeningCenterAc tivities.shtml).

\section{CRTIEC's Tier 3 Language and Early Literacy Interventions}

A Tier 3 instructional intervention of increased intensity is also being developed and validated (Goldstein \& Kaminski, 2010). Instruction in each area is delivered using brief, reading-related, intensive, engaging, and focused activities using games, movement, and song to increase engagement and opportunities to respond (online at http://www.crtiec. org/Resources/example_t3.shtml). Rather than providing children with additional supplemental activities linked to the core Tier 1 curriculum as in the SFLCs, the Tier 3 interventions are focused on a restricted number of evidence-based skills in the four domain skill areas.

For example, in the language domain, the focus is on building children's (a) knowledge of core vocabulary (i.e., nouns, verbs, descriptive words, prepositions), (b) use of core vocabulary in simple sentences, and c) comprehension of literal and referential questions about simple sentences. Instruction unfolds in the following format: (a) interactive storybook reading provides the context, (b) vocabulary words for the lesson are introduced, c) practice using words in games and activities occurs. In the phonological awareness domain activities employ the following format: (a) letter naming game; (b) introduction/review of target skill; (c) guided practice of target skill in early literacy game; and (d) contextualization of target skill in song, poem, or finger play. Tier 3 instruction requires a trained interventionist to deliver instruction and will take place in a designated area of the classroom during Center time. Interventions are scheduled for 5-10 minutes three times a week, with the games conducted individually or in groups of no more than three children.

\section{CRTIEC's Decision-Making Framework}

Measures appropriate for interventional decision making in RTI need to accurately differentiate between children who are performing at an adequate level in a given skill area versus children who are not and could benefit from more intensive intervention. Measures also need to be sensitive to changes in children's growth over relatively short periods of time. Sensitivity to short-term growth allows evaluation of the impact of an implemented intervention and informs decision making about the appropriate level of intervention required (Greenwood, Carta, et al., 2008). The Individual Growth and Development Indicators (IGDIs) are available measurement tools appropriate for early childhood RTI applications (Carta, Greenwood, Walker, \& Buzhardt, 2010; Greenwood, Carta, et al., 2008; McConnell \& Missall, 2008).

IGDIs were originally developed in an effort to create measures for screening and progress monitoring similar to $\mathrm{K}-12$ measures such as Curriculum-Based Measurement (CBM; Shinn, 2008) and Dynamic Indicators of Basic Early Literacy Skills (DIBELS; Kaminski, Cummings, PowellSmith, \& Good, 2008). IGDIs are a recognized approach that early interventionists can use for screening decisions and for monitoring the growth and development of young children (Priest et al., 2001; Snyder, Wixson, Talapatra, \& Roach, 2008; VanDerHeyden \& Snyder, 2006). IGDIs with associated decision criteria (i.e., benchmarks) are beginning to emerge in early childhood as resources for program accountability as well as for individual RTI purposes (Greenwood, Carta, et al., 2008; McConnell \& Missall, 2008).

\section{Infant and Toddler IGDIs}

Five IGDIs are available for infants and toddlers (Carta, Greenwood, Walker, \& Buzhardt, 2010). They include (a) the Early Communication Indicator (ECI; Greenwood, Carta, Walker, Hughes, \& Weathers, 2006), (b) the Early Movement Indicator (EMI; Greenwood, Luze, Cline, Kuntz, \& Leitschuh, 2002), (c) the Early Social Indicator (ESI; Carta, Greenwood, Luze, Cline, \& Kuntz, 2004), (d) the Early Problem Solving Indicator (EPSI; Greenwood, 
Walker, Carta, \& Higgins, 2006), and (e) the Indicator of Parent-Child Interaction (IPCI; Baggett \& Carta, 2006) (see also online at www.igdi.ku.edu).

The IGDIs are administered in a play context wherein a familiar adult and the child engage in play for 6 to 10 minutes, depending on the particular IGDI. Another adult observes the play and records the frequency of occurrence of up to four or five key skills, depending on the particular measures being used. With the ECI, for example, the key skills include gesture, vocalization, single words, and multiple words. In each case, scores are the rate per minute for each key skill as well as a total score based on a combination of the key skill scores. These data are graphed and comparisons between (a) the child's score and normative benchmark scores for children that month of age (screening) and (b) the child's score and prior scores (progress monitoring) can be made.

These measures are supported by the IGDI website, which provides information and resources for a full range of needs for early childhood service providers who want to conduct universal screening and progress monitoring with their infants and toddlers. A web-based child data management, data collection, and reporting system is included in the IGDI data system, and the resources available include initial orientation information, training materials, online certification, certification videos, sample administration videos, assessment forms, and checklists. Customized dynamic reports of child progress, interventions used, demographic information, staff implementation data, and child early communication data including individual growth charts are available to users of the online system (Buzhardt et al., 2010).

\section{Preschool IGDIs}

McConnell and his colleagues developed preschool early literacy measures of vocabulary, rhyming, and alliteration (Missal \& McConnell, 2010).

\section{Picture Naming}

The Picture Naming IGDI is a measure of oral language development. Picture Naming items are 8" x 5" cards that portray images of objects common to the environments of preschool-aged children (e.g., food, transportation, animals, clothing). However, because the cards are randomized for each administration, a child sees only a small subset in a 1minute administration. Each administration is preceeded by presentation of four random cards as warm-up followed by the 1-minute administration. The score is the number of cards correctly named in 1 minute.

\section{Rhyming}

The Rhyming IGDI is a measure of phonological awareness. Each Rhyming item includes four objects presented on
$8 " \times 5$ " cards: one target picture at the top and three pictures of possible rhyming items along the bottom. Like Picture Naming, cards are presented one at a time, and the items on each card are always labeled aloud by the administrator. Rhyming has two standard sample items, four random sample items, and many test items that are selected randomly from a shuffled set of cards prior to administration. The number of correctly identified rhymes in 2 minutes is the score.

\section{Alliteration}

Like the Rhyming IGDI, the Alliteration IGDI is a measure of phonological awareness. The Rhyming and Alliteration IGDIs are also similar in presentation, administration, and scoring. Each Alliteration IGDI item presents four objects on a $8 " \times 5 "$ card: one target picture at the top and three pictures along the bottom, one of which begins with the same sound as the target picture. Cards are presented one at a time, and items on each card are labeled aloud by the administrator. The Alliteration has two standard sample items, four random sample items, and many test items that are shuffled prior to administration so that each administration yields a different set of test cards. The number of alliterations from test items identified correctly in 2 minutes is the score. Like the Infant and Toddler IGDIs, supports for using preschool IGDIs are available at the website (http:// ggg.umn.edu).

\section{Preschool IGDIs [Version 2] Picture Naming and Sound Identification}

At present, significant work is in progress to improve and refine the preschool IGDIs (Wackerle-Holman \& Bradfield, 2010). Research and development of the new Preschool IGDIs has covered the domains of language and early literacy development: Oral Language, Alphabet Knowledge, Phonological Awareness, and Comprehension. In this effort, preschool IGDIs for language and early literacy are going through a process of improvement in psychometrics (i.e., Picture Naming, Rhyming, and Alliteration) and creation of new measures (e.g., Definitional Vocabulary, Which One Doesn't Belong, Sound Blending, etc.). Just two elements of this innovation are improved item discriminability and analyses of item difficulty using Rasch modeling. Presently, only the measures of Oral Language (Picture Naming) and Alphabet Knowledge (Sound Identification) are available for use. Picture Naming supports decisions regarding intervention intensity levels for oral language; Sound Identification supports a similar function for Alphabet Knowledge.

Picture Naming consists of four sample cards and 15 test cards, each depicting a familiar object. The child is asked to name each card. The score on this untimed test is the number of pictures correctly named. Sound Identification consists of 
the same number of cards; however, each card depicts three letters (upper and lower case). The child is asked to point to the letter that makes the sound modeled by the test administrator. The score on this untimed test is the number of letters correctly identified. Based on a benchmark level of performance separating the performance of children in Tier 1 versus Tiers 2 and 3 risk levels, the difference in IGDI growth trajectories between fall and spring of the preschool year can be seen (see Figure 3).

Over the large sample in CRTIEC's multisite descriptive study, 33\% of children (Picture Naming) and $40 \%$ of children (Sound Identification) were eligible to receive either Tier 2 or 3 instructional interventions. As would be expected, these proportions of children varied widely by type of preschool program. In private pay programs, only $21 \%$ (Picture Naming) and 6\% (Sound Identification) children needed Tier 2 or 3 supports compared to $40 \%$ in Head Start and $37 \%$ in Pre-K, respectively (Carta, Greenwood, \& Atwater, 2010). Thus, as expected of measures for screening and progress monitoring in RTI, these IGDIs discriminated among children of different levels of risk defined by benchmarks referenced to criterion measures and also displayed growth over time. As regards growth over the preschool year, Tier 2 or 3 eligible children start radically lower than children in Tier 1 in the fall and, without change in services, did not close the gap with Tier 1 children on either measure through to the spring. These data support the feasibility and value of the RTI-MTSS logic to accelerate children's rates of progress in preschool.

\section{AN EXAMPLE OF STATE-BASED EARLY CHILDHOOD PROGRAMS IMPLEMENTING RTI}

Even though the majority of states reported that they were merely in preparation to implement EC RTI, reports describing state-based early childhood RTI programs are emerging (see the Pre-K Roadmap). Some of the first RTI implementations occurred in Early Reading First and state Pre-K programs. For example, the RTI program implemented at the Valley View District 365U-Early Childhood

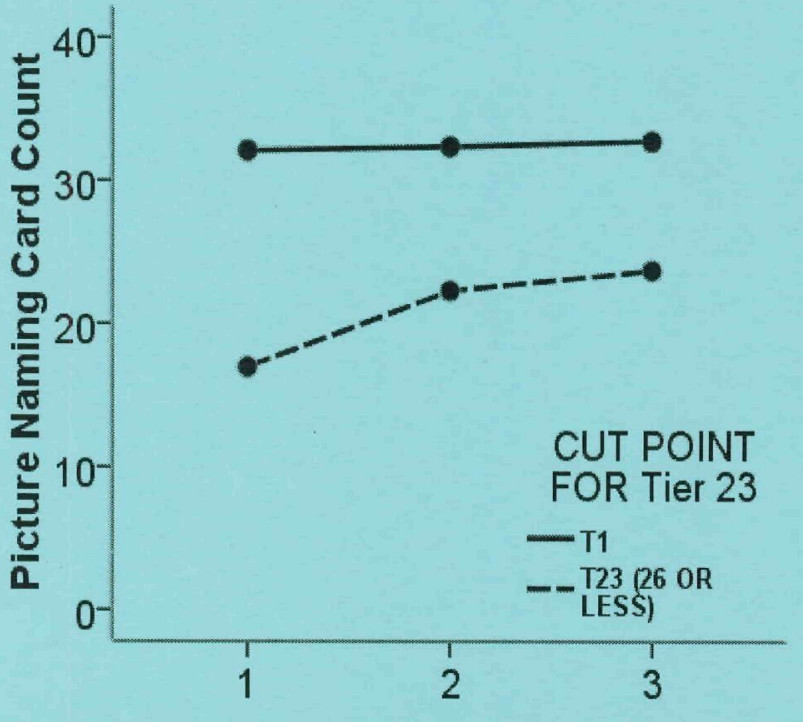

Measurement Occasions

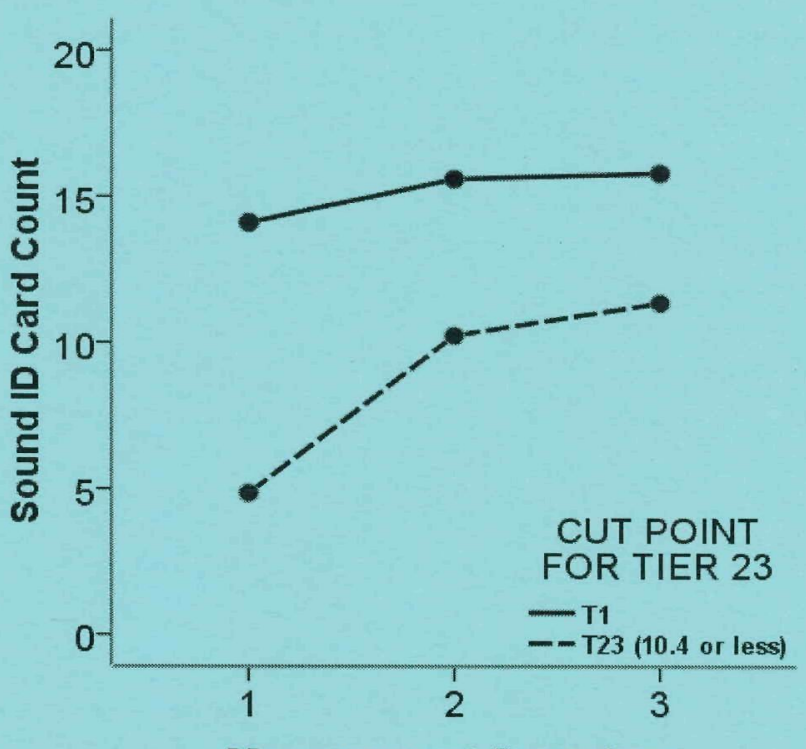

Measurement Occasions

\section{FIGURE 3}

Growth in Picture Naming and Sound Identification IGDIs for children above (Tier 1) versus below benchmarks (Tier $2 / 3$ ) over three occasions during the preschool year. Predictive benchmarks in fall of preschool were based on above or below a spring outcome performance standard score of $\mathbf{- 1}$ SD or $\mathbf{8 5}$ on the Peabody Picture Vocabulary Test (Picture Naming IGDI) and the Test of Preschool Early Literacy - Print Knowledge scale (Sound Identification IGDI). Predictive utility in terms Sensitivity and Selectivity accuracy were set at $\mathbf{8 4} \%$ for Picture Naming and $\mathbf{7 0} \%$ for Sound Identification, respectively. 
Center in Romeoville, IL, covers both early academics and behavior domains (Nylander, 2009). The RTI components used included locally collected data on academic and behavioral progress for use in instructional decision making. Combined with these data were three levels of hierarchical support: Tier 1, 2, and 3 (Vaughn \& Chard, 2006). At Tier 1 , an evidence-based core curriculum with a scope and sequence of skills is used to serve all children in the program. The Tier 1 teaching approach at Valley View is intentional. The role of the teacher was to implement the core curriculum and teach the targeted skills. The roles of the curriculum and the teacher were to create engaging learning opportunities for children. Another RTI component in Tier 1 is universal fall and winter screenings for the purpose of identifying children falling below benchmark. For this purpose, the preschool early literacy IGDIs (Version 1) were used (e.g., children's picture naming fluency as an indicator of oral language development) (McConnell, 2000).

The intervention used for promoting social and emotional competence was Positive Behavior Intervention Support (PBIS; See http://www.pbisillinois.org/) that also spans Tiers 1, 2, and 3. At Tier 1, common classroom rules are used: Be Safe, Be Ready, Be a Super Friend. Additional rules routinely taught to all children are Eyes on Teacher, Listening Ears, Hands and Feet to Self, Share, and Take Turns.

The children served in Tier 2 were those identified in the universal periodic screenings as children not benefiting from the core Tier 1 curriculum. Helping support teachers and children in Tier 2 and 3 was the Valley View Targeted Intervention and Problem-Solving Team (TIPS) team. The goals at Tier 2 were to provide additional attention, narrower focus, greater support, and more opportunities to practice. Guided by supporting evidence, small group work and embedded instructional approaches were used at Tier 2. By imbedding response opportunities in natural routines, it is possible to increase children's opportunities to respond. This is accomplished by modifying environmental arrangements, curriculum, and by adding peer support. Additionally, specialists (e.g., SLPs, Master Teacher) were available to assist teachers and teachers monitor progress over time more frequently.

The goal of Tier 3 instructional intervention was to provide intensive, individualized intervention. For preacademics, this included explicit instruction using research-based curricula. It also included peer-mediated strategies, modeling, verbal and nonverbal helping strategies, prompting techniques, time delay, mand model training, and incidental teaching. Progress monitoring was increased to daily. Tier 3 also benefitted from outside consultation and support to the classroom.
Other components included the following:

- The building leadership team. The team coordinated the following schoolwide activities: curriculum evaluation and selection, positive behavioral intervention strategies, parent involvement, and data analysis/in terpretation.

- Effectiveness. Evaluating the effort based on the proportions of children in the three tiers at fall, winter, and spring time points during the 2008-2009 school year, the number of children in Tier 3 instruction declined at each successive time point: $30 \%, 18 \%$, and $10 \%$. Similarly, for Tier 2 , there was a drop in children at $55 \%, 47 \%$, and $40 \%$ from fall to spring. Also, more children were being served in Tier 1 , at $16 \%, 35 \%$, and $50 \%$, over the school year.

- Lessons learned. We were learning from our RTI implementation right alongside the researchers and the literature. For example, it was challenging to find evidence-based curriculum combined with developmentally appropriate practices. We understood that RTI was for all children, not just SPED. It was challenging but important that we defined the RTI role of each discipline in our model (i.e., psychology, social work, occupational therapy, physical therapy, speech and language, and special education). Other important supports were building relationships with our local university faculty for research and consultation, being proactive about explaining RTI to parents and families, interpreting Tier 2 and 3 results from the data, communicating the message never use RTI to keep children out of special education, and using consultants to provide coaching onsite as well as workshops for staff to promote implementation of RTI practices. We also made progress finding and developing our Tier 2 and 3 interventions, designing the role of the TIPS problem-solving team, and acquiring more materials in Spanish.

In these sections, we discussed the status of early childhood RTI implementation, emerging resources and models, ongoing research and development to develop evidencebased component practices for use in RTI (Tier 2, Tier 3, and measures), and this example of a state-based RTI program. We now turn to discussion of challenges and myths regarding RTI in early childhood that need to be addressed.

\section{CHALLENGES TO THE RTI APPROACH IN EC}

Lack of universal access to early education and an incomplete system of preschool education in America presents a formidable challenge to our ability to implement RTI to 
benefit all young children. Addressing this challenge is larger than the purview of this article. However, cognizance of this challenge sharpens thinking about how to address system-level factors that impede adoption of an early childhood RTI framework serving all children. The most significant challenges to the RTI approach reported by state directors and coordinators were (a) insufficiently trained personnel, (b) lack of resources needed to develop the RTI infrastructure, (c) lack of Tier 2 and 3 intervention strategies, (d) lack of knowledge in how to create an RTI model, and (e) lack of evidence-based Tier 1 instruction, among others (e.g., lack of administrative support, progress monitoring measures; Linas et al., 2010) (see Table 1).

Survey respondents also indicated that their greatest concerns about implementing RTI was the lack of professional developments (69\%), lack of funding (64\%), and lack of or unclear policy (44\%), among others, including delay in services $(9 \%)$ (see Table 2 ). We briefly discuss some of these challenges and concerns.

\section{Workforce Quality}

The teacher preparation requirements of the workforce in early childhood are fewer than those of the $\mathrm{K}-12$ teacher. Few programs have teachers with bachelors degrees. Many of the teachers, aides, and caregivers who work in early childhood programs are underpaid, and there is a high rate of turnover. Early childhood educators are currently under-trained in how to effectively implement early literacy instructional activities and in how to engage in interactions that promote language skills (Emergent and Early Literacy Workshop, 2000; Mashburn, 2008). This is imminently troubling, as broad scale studies have demonstrated the powerfully positive impact on preschoolers' language and literacy abilities of skillful teachers. Particularly effective are teachers who engage in instructionally supportive interactions with children with intentional emphasis on encouraging, responding to, and expanding on their students' talk (Howes et al., 2008; Mashburn, 2008). Add on to this challenge the additional burden of implementing the essential components of an RTI system (screening, progress monitoring, decision making, and implementation of increased levels of intervention), and one quickly sees that the challenge of undertrained personnel is not a small one.

\section{Lack of Knowledge and Resources}

For some, early childhood RTI is somewhat like "old wine in new bottles." Effective methods for differentiating levels of instruction to match student need have been well articulated and broadly used within the field of early childhood special education (Sandall et al., 2002). For early childhood, the novelty of an RTI model is its provision of a comprehensive framework to conceptualize how to meet the educational needs of all students, rather than compartmentalizing students into regular or special education. RTI strives to incorporate the most effective teaching strategies, once used only with students qualifying for special education services,

\section{TABLE 1}

\section{RTI Challenges Reported by State Early Childhood Directors/Coordinators}

Please rate each of the following potential challenges to early childhood programs that wish to begin implementing RTI model

\begin{tabular}{|c|c|c|c|c|c|c|}
\hline Challenges & $\begin{array}{l}\text { Little/No } \\
\text { Challenge }\end{array}$ & $\begin{array}{c}\text { Some } \\
\text { Challenge }\end{array}$ & $\begin{array}{l}\text { Moderate } \\
\text { Challenge }\end{array}$ & $\begin{array}{l}\text { Significant } \\
\text { Challenge }\end{array}$ & $\begin{array}{c}\text { Rating } \\
\text { Average }\end{array}$ & $\begin{array}{c}\text { Response } \\
\text { Count }\end{array}$ \\
\hline Insufficient trained personnel to implement RTI & 3 & 10 & 14 & 20 & 3.09 & 47 \\
\hline Lack of resources to develop the infrastructure & 3 & 12 & 12 & 20 & 3.04 & 47 \\
\hline Lack of Tier 2 and Tier 3 intervention strategies & 3 & 10 & 16 & 18 & 3.04 & 47 \\
\hline Lack of knowledge in how to create an RTI model & 3 & 8 & 21 & 15 & 3.02 & 47 \\
\hline Lack of evidence-based Tier 1 programs & 5 & 19 & 13 & 10 & 2.60 & 47 \\
\hline Lack of administrative support and leadership & 5 & 18 & 16 & 8 & 2.57 & 47 \\
\hline Lack of progress monitoring measures & 9 & 14 & 18 & 6 & 2.45 & 47 \\
\hline Difficulty in establishing collaborative relationship & 8 & 22 & 11 & 6 & 2.32 & 47 \\
\hline \multicolumn{6}{|c|}{$\begin{array}{l}\text { Other (please specify) } \\
\text { Answered Question } \\
\text { Skipped Question }\end{array}$} & $\begin{array}{r}6 \\
47 \\
5\end{array}$ \\
\hline
\end{tabular}

Note. Rating differential: 1 = Little/No Challenge, $2=$ Some Challenge, $3=$ Moderate Challenge, $4=$ Significant Challenge 
TABLE 2 2010 Concerns about RTI in Early Childhood

Please indicate any concerns you have about the implementation of RTI

\begin{tabular}{|c|c|c|c|}
\hline Answer Options & $\begin{array}{l}\text { Response } \\
\text { Percent }\end{array}$ & $\begin{array}{c}\text { Response } \\
\text { Count }\end{array}$ & Respondents \\
\hline $\begin{array}{c}\text { Lack of professional } \\
\text { development }\end{array}$ & $68.9 \%$ & 31 & 45 \\
\hline $\begin{array}{l}\text { Lack of funding } \\
\text { No policy or }\end{array}$ & $64.4 \%$ & 29 & 45 \\
\hline unclear policy & $44.4 \%$ & 20 & 45 \\
\hline Lack of infrastructure & $40.0 \%$ & 18 & 45 \\
\hline Lack of staffing & $37.8 \%$ & 17 & 45 \\
\hline Lack of systems & $31.1 \%$ & 14 & 45 \\
\hline Comments: & $26.7 \%$ & 12 & 45 \\
\hline $\begin{array}{l}\text { Lack of state } \\
\text { standards }\end{array}$ & $15.6 \%$ & 7 & 45 \\
\hline $\begin{array}{l}\text { Other (please specify } \\
\text { in Comments box) }\end{array}$ & $\begin{array}{r}11.1 \% \\
8.9 \%\end{array}$ & 5 & 45 \\
\hline \multicolumn{3}{|c|}{$\begin{array}{l}\text { answered question } \\
\text { skipped question }\end{array}$} & $\begin{array}{r}45 \\
7\end{array}$ \\
\hline
\end{tabular}

with careful systems of data collection, decision making, and resource allocation, to best meet the educational needs of all children in a cost- and time-efficient manner. Thus, the challenge here lies in reinventing existing systems of education. Obviously, this is not an easy task.

\section{Lack of Evidence-Based Intervention Strategies for Tiers $2 \& 3$}

Given the lack of core early language and literacy curricula with strong evidence of effectiveness, it would make sense to assume that little is known about strategies that would work at higher levels of intensity, that is, Tiers 2 and 3. Fortunately, this is not so. From the fields of Early Childhood Special Education (ECSE) and Speech and Language Pathology in particular, we have decades of research that documents the positive effects of specific interventions for language development (Craig-Unkefer \& Kaiser, 2002; Girolametto, Weitzman, \& Greenberg, 2004; Kouri, 2005). What is lacking is a manualized approach that guides early childhood educators on how to implement these strategies within the context of the day-to-day operations of the classroom.

Children at risk for learning difficulties make the strongest gains in skill when provided with frequent explicit teacher-directed interactions that are structured, sequenced, and targeted (Justice \& Kaderavek, 2004), in addition to learning activities that are embedded within ongoing classroom routines (Sandall et al., 2002). While early childhood special educators or other educational specialists are trained to utilize these evidence-based strategies with children with identified special education needs, general early childhood educators tend to be trained to plan instruction at the classroom level. Thus, when addressing this challenge, the need is not for developing and validating new intervention strategies, but rather is to test the effectiveness of these established interventions within the new context of an RTI framework. This challenge also specifies a strong need to develop systems of professional development and strategies for resource allocation that support the necessary decision-making models and intervention implementation needed to make an EC RTI model successful.

\section{Lack of Evidence-Based Curricula}

The core Tier 1 curriculum sets the stage for RTI because the effectiveness of the core curricula largely determines the learning success of all the children experiencing it. Because an evidence-based curriculum has been shown to produce better outcomes for children compared to other alternatives, fewer children in a program using such a curriculum will likely need more intensive Tier 2 and 3 interventions. We expect the number of children needing these Tier 2 and 3 interventions to be larger in programs that are not using an evidence-based curriculum. Unfortunately, not many evidence-based curricula for teaching language and early literacy exist.

In the Preschool Curriculum Evaluation Research (PCERS) initiative (online at http://ies.ed.gov/ncer/pubs/ 20082009/in dex.asp), researchers sought to identify the impact of 14 different curricula on five student-level outcomes (reading, phonological awareness, language, mathematics, and behavior) and six classroom-level outcomes (classroom quality, teacher-child interaction, and four types of instruction). Russell et al. (2007) reported that only 2 of the 14 intervention curricula evaluated in the PCERS had impacts on the student-level outcomes for the prekindergarten. year. DLM Early Childhood Express supplemented with Open Court Reading Pre-K positively affected reading, phonological awareness, and language. Pre-K Mathematics supplemented with DLM Early Childhood Express Math software curricula positively affected mathematics. Russell further found that 8 of the 14 treatment curricula had a positive effect on the prekindergarten classroom-level outcomes. Bright Beginnings affected early literacy instruction and phonological awareness instruction. Creative Curriculum (as implemented by the North Carolina team but not by the Tennessee research team) affected classroom quality, teacher- child interaction, 
early literacy instruction, and early language instruction. Creative Curriculum combined with Ladders to Literacy affected early literacy instruction. Of the more than 20 curricula at the What Works Clearinghouse (http://ies.ed.gov/ncee/wwc), only two preschool curricula demonstrated strong evidence of a positive effect on reading or reading-related outcomes with no overriding contrary evidence.

Kaminski \& Carta (2010) assessed the instructional design quality of 10 preschool language and early literacy curricula used in 67 preschool classrooms in programs in 4 states evaluating skills taught and the methods of instruction used (see Table 3). They reported instructional design quality outcomes in support of four domains: vocabulary and oral language, alphabet knowledge, phonological awareness, and listening comprehension. The mean quality ratings were $63 \%(S D=18), 63 \%,(S D=18), 64 \%(S D=$ $18)$, and $40 \%(S D=18)$, respectively (see Table 4$)$. As shown, curricula were more or less comprehensive in their coverage of all of these domains.

\section{Administrative Support and Resources}

Much can be said about the importance of administrative support and resources, because implementation requires fundamental differences in how services are planned, staffed, and provided. At the basic level, support for providing time in teachers' days and weeks for teaming and decision making is a critical component in RTI. Similarly critical is the ability to create flexible and dynamic staffing structures to carry out RTI components. Lastly, RTI cannot happen if the resources needed for providing the appropriate professional development and consultation services are not forthcoming.

\section{TABLE 3}

List of Language and Early Literacy Curricula

\section{Curricula}

Number of

Brookes: Ladders to Literacy +

Handwriting Without Tears

Classrooms

Harcourt Brace: Story Town

17

Scholastic: Building Language and Literacy

11

Creative Discoveries + SEEDS of Early

Literacy Supplement

AEPS: Assessment, Evaluation and

Programming System

SRA: Open Court

Creative Curriculum

Houghton Mifflin

Jolly Phonics

Lucy Calkins Writers' and Readers' Workshop

\begin{tabular}{|c|c|c|c|c|}
\hline \multicolumn{5}{|c|}{$\begin{array}{c}\text { TABLE } 4 \\
\text { Instructional Design Quality Ratings by } \\
\text { Domains }\end{array}$} \\
\hline $\begin{array}{l}\text { Instructional } \\
\text { Domain }\end{array}$ & Mean & SD & Minimum & Maximum \\
\hline Phonological & & & & \\
\hline & 63.0 & 17.9 & 25 & 83 \\
\hline $\begin{array}{l}\text { Knowledge } \\
\text { Vocabulary and }\end{array}$ & 62.5 & 18.6 & 0 & 83 \\
\hline $\begin{array}{l}\text { Oral Language } \\
\text { Listening }\end{array}$ & 63.9 & 18.3 & 0 & 83 \\
\hline Comprehension & 60.2 & 22.0 & 0 & 83 \\
\hline
\end{tabular}

\section{RTI Myths in Early Childhood}

In addition to these challenges, a number of myths have developed about what RTI for early childhood is and how it should be implemented. The following are myths and responses referred to or identified by CRTIEC staff.

Myth 1: RTI replaces early childhood special education and its procedural safeguards, and if a district has implemented RTI, it means that students cannot be referred for special education evaluation.

Preschool children and their families have a host of legal rights and privileges for gaining access to special education and related services, and RTI models must not reduce or restrict those rights and privileges. RTI does not replace early childhood special education and its safeguards, and children are not required to undergo an RTI process prior to referral or evaluation for special education services (Posney, 2010). A parent or educator has the right to request an initial evaluation to determine whether a child has a delay or disability, and the existence of an RTI process does not weaken that right.

\section{Myth 2: RTI necessarily delays referral, eligibility, or the onset of special education services.}

As noted in Myth 1 above, RTI should not cause a delay. However, an effective RTI model with young children should increase children's access to helpful services and not lead to delays in referral, eligibility determination, or the onset of special education and related services. The goal of RTI is to broaden the range of intervention strategies employed in general education, not to deny students access to services or supports they may need to be successful. The official position on RTI by the CEC (2007) specifically states: "The RTI process shall not delay the referral of a child who is suspected of having a disability for a comprehensive evaluation. 
Children with identified disabilities may not be required to go through an RTI process in order to receive special education and related services" (p. 1). RTI is a prevention model that is designed to provide high-quality opportunities for learning before a child is eligible for special education and related services. When such experiences appear to be limited or absent, a tiered model of instruction should prove helpful in deciding whether a child should be referred for an evaluation for special education services.

\section{Myth 3: RTI consists of 3 tiers of increasingly individualized instruction with children with disabilities being in Tier 3.}

There is no ideal number of tiers of instruction. The general notion of RTI is to have a continuum of increasingly intensive or alternative options to meet the needs of the population served. The number of instructional options will vary, and there is no consensus at this point on the extent of procedural variation that might be considered a separate tier of instruction. In an RTI model, students would be identified for increasing levels of support in higher tiers if they did not demonstrate adequate growth in a particular tier. Students with identified disabilities may be at any tier of instruction depending on their progress and their performance relative to benchmarks on the skills of concern.

\section{Myth 4: Evidence-based curricula and instructional practices are available to support the implementation of RTI approaches in early education.}

While the list of curricula and instructional practices with demonstrated effectiveness in producing short-term outcomes for children is growing, the evidence base of curricula and instructional strategies to support children's school readiness and to provide intervention across multiple tiers of an RTI model is still in its infancy. Information about effective practices and curricula to promote early literacy and other domains related to school readiness can be found in the What Works Clearinghouse (http://ies.ed.gov/ ncee/wwc/reports/Topic.aspx?tid=13), the report from the National Early Learning Panel (http://www.nifl.gov/early childhood/NELP/NELP09.html), and the report from the Preschool Curriculum Evaluation Research Consortium (http://ies.ed.gov/ncer/pubs/20082009/index.asp). While the strength of evidence is stronger in some areas than others, studies showing that effective interventions and curricula can be scaled up and implemented and sustained in communitybased early education programs are exceedingly rare. Furthermore, only a few studies have been published to demonstrate the effectiveness of interventions that might be used in Tier 2 or Tier 3 to support children who need more intense or individualized interventions to demonstrate growth toward school readiness outcomes. Finally, the infrastructure to provide wide-scale and high fidelity implementation of these curricula and instructional strategies to be used in any tier of intervention is only beginning to develop.

\section{Myth 5: Assessment tools that can be used within RTI approaches to identify preschool-aged children with learning problems or to monitor young children's progress in response to intervention are currently lacking.}

To date, tools for assessing children's growth and development are still few in number and not widely available. A growing list of measures (e.g., Individual Growth and Development Indicators [http://ggg.umn.edu], mClass Circle [http://www.wirelessgeneration.com/solutions/mclass-circle. html], Get Ready to Read [http://www.getreadytoread.org]) predict later reading performance and can be used for instructional decision making in prekindergarten settings. It should be noted that even these measures have not been field tested widely and await both longitudinal studies to examine their general psychometric properties and intervention studies to explore their sensitivity to treatment effects. However, researchers and local education agencies are making rapid progress both in the design and evaluation of screening and progress monitoring measures and in developing systems that help early childhood educators apply and use these measures. As this development work continues, the array of tools available to practitioners will grow.

\section{Myth 6: Once children are identified as needing instruction at a specific tier, they will not change tiers over the course of the academic year.}

RTI is designed to be a dynamic model of service delivery, adjusting the teaching approach as a child's progress dictates. Children who demonstrate response to intervention at a given tier (i.e., demonstrate growth meeting a specific benchmark) may move to a less intensive tier. Similarly, if children show inadequate growth to meet a benchmark at a specific tier, they may be moved to a more intensive level of intervention. This is a critical issue in early childhood programs, where the time is often very short (usually less than a year) before matriculation to $\mathrm{K}-5$ programs. In these cases, frequent assessment and movement to a more appropriate level of instruction is critical.

\section{Myth 7: While RTI might be an appropriate model of providing a greater level of instructional support to school-aged children, most RTI models for prekinder- garten children focusing on early literacy are based on developmentally inappropriate expectations for young children.}

RTI, particularly in early childhood, must be designed to be individually appropriate for participating children. There is no single RTI approach for prekindergarten children 
focusing on early literacy, but a critical component of all RTI models is the use of a strong Tier 1 founded on an evidence-based curriculum. It is important to note that RTI approaches focusing on early literacy in Pre- $\mathrm{K}$ are not focused on teaching children to read but rather on emergent literacy skills that are appropriate for preschool children. If RTI approaches in early literacy are to be successful in improving children's readiness for school, they should focus on providing children with instruction on the set of pre-literacy skills known to be predictors of academic performance in kindergarten. In early education, these curricula are typically implemented within the context of teacherdirected group interaction and embedded in classroom routine activities. As with all intentional teaching, instructional approaches must be individually as well as developmentally appropriate to meet the short- and long-term needs of any particular child.

\section{Myth 8: RTI reinforces the practice of "ability grouping," which may be detrimental to young children's self-esteem.}

While tiered interventions in some RTI models may include homogenous groups of children, these groupings will occur only for a small part of a day and can (and, we believe, should) be embedded in a comprehensive and inclusive program. RTI allows classroom staff to provide a level of instructional intensity that a given child needs to promote success. Rather than "tracks," RTI promotes dynamic allocation of instructional resources based on the current needs of individual children. We are unaware of research that validates the myth that grouping children based on their level of need lowers children's self-esteem. On the other hand, much research shows that children who experience early success go on to achieve healthy academic and social outcomes.

\section{IMPLICATIONS}

Seeking to achieve greater effectiveness in educating the nation's youth, the RTI approach is increasingly being implemented in US schools. In contrast to past models of waiting to serve children with learning and behavioral problems later in their schooling as they became eligible for disability services, RTI embraces intervening as soon as students are first show signs of not making progress. In addition to administrative support of RTI and a qualified, skilled staff, RTI presumes use of evidence-based practices, universal screening and progress monitoring with decision making, and multiple systems of support.

The implications for research, development, and evaluation lie in the production of the needed practices, interventions, and measures, with evidence showing that they indeed produce measurably superior results. The test bed for conducting this work needs to be in the context of typical early childhood settings and services with typical early childhood staff serving as implementers. As is clear in this article, RTI in early childhood is an emerging practice with a promise of leading to greater levels of effectiveness. In the areas of screening and progress monitoring measurement (e.g., the IGDIs) and in the models translating RTI to the early childhood system and profession, practices are most advanced. An increasing number of state-based local programs are beginning to employ RTI in preschool; relatively fewer are using RTI with infants and toddlers. However, few language and early literacy curricula (Tier 1) are supported by strong evidence, and gaps remain in other aspects of needed infrastructure and practice. In addition to the challenges and myths described above, greater efforts are needed at integrating the social-emotional with language and early literacy domains in early childhood RTI models, interventions, and measures.

Implications for practice lie in implementing RTI models in local programs and refining them from year to year: the practices, procedures, and measures used in an effort to promote improved annual outcomes for children. Creative efforts to work collaboratively across early childhood sectors to serve all children by blending resources; determining roles and responsibilities; creating teams for selecting practices, reviewing child data, and making intervention decisions appear to point the way to overcoming the absence of a unified system and of reaching greater effectiveness.

The implications for policy at the state and federal levels call for unifying the early childhood system through, if not bridging sectors, at least removing barriers to the provision of services to children with different needs in inclusive, least restrictive settings where services by various professionals can be provided. Additionally, policies clarifying the role of RTI within and across early childhood system sectors will enable progress toward serving the needs of all children.

\section{SUMMARY AND CONCLUSION}

The purpose of this article was to survey the current status of RTI implementation in early childhood settings serving children ages birth to 5 years old prior to kindergarten. The goal was not an exhaustive review but rather examination of implementation as reported by state-level directors and coordinators. We pointed to advances in RTI models, practices, and examples in early childhood. We examined the socio-emotional, language, and early literacy skills that research says should be the outcomes of early childhood education. We followed with a description of the early childhood system and the discipline that are the contexts for the RTI approach. We examined aspects of early childhood that are a fit to RTI. We reported current areas of accomplishment, 
ongoing research and development, and policy needed in support of early childhood RTI implementation. We discussed challenges, including myths that may serve as barriers to implementation and that need to be mitigated in future research, professional development, and practice. Clearly, EC RTI is emerging, and it is possible to see trends toward greater levels of future implementation. The greatest overriding influence on future implementation will be the increasing presence of evidence of greater effectiveness and a widening choice of component practices for use in implementation that are based on measurably superior results and that are feasible because they overcome the challenges inherent in early childhood.

\section{REFERENCES}

Badian, N. A. (2000). Do preschool orthographic skills contribute to prediction of reading? In N. Badian (Ed.), Prediction and prevention of reading failure (pp. 31-56). Timonium, MD: York Press.

Baggett, K. M., \& Carta, J. J. (2006). Using assessment to guide socialemotional intervention for very young children: An individual growth and development indicator (IGDI) of parent-child interaction. Young Exceptional Children Monograph Series, 8, 67-76.

Bagnato, S. J. (2007). Authentic assessment for early childhood intervention: Best practices. New York: Guilford Press.

Barnett, W. S., Epstein, D. J., Friedman, A. H., Sansanelli, R., \& Hustedt, J. T. (2009). The state of preschool 2009. National Institute of Early Education Research, Rutgers. Retrived from http://nieer.org/yearbook/pdf/yearbook.pdf

Belfield, C. R. (2005). The cost savings to special education from preschooling in Pennsylvania. Harrisburg, PA: Pennsylvania Build Initiative, Pennsylvania Department of Education. Retrieved from http://www.portal.state.pa.us/portal/server.pt?open $=18 \&$ objID $=3$ $81892 \&$ mode $=2$

Berkeley, S., Bender, W. N., Peaster, L. G., \& Saunders, L. (2009). Implementation of response to intervention: A snapshot of progress. Journal of Learning Disabilities, 42(1), 85-95.

Biemiller, A. (2006). Vocabulary development and instruction: A prerequisite for school learning. In D. K. Dickinson \& S. B. Neuman (Eds.), Handbook of Early Literacy Research (Vol. 2, pp. 41-51). New York: Guilford Press.

Block, C. C., Gambrell, L. B., \& Presley, M. (2002). Improving comprehension instruction: Rethinking research, theory, and classroom practice. New York: Jossey-Bass.

Burgess, S. R., \& Lonigan, C. J. (1998). Bidirectional relations of phonological sensitivity and prereading abilities: Evidence from a preschool sample. Journal of Experimental Child Psychology, 70, 117-141.

Buysee, V., \& Peisner-Feinberg, E. (2009). Recognition and Response. Early Childhood RTI Roadmap, 7-8.

Buzhardt, J., Greenwood, C. R., Walker, D., Carta, J. J., Terry, B., \& Garrett, M. (2010). Web-based tools to support the use of databased early intervention decision making. Topics in Early Childhood Special Education, 29(4), 201-214.

Carta, J. J., Atwater, J. B., Schwartz, I. S., \& Miller, P. A. (1990). Applications of ecobehavioral analysis to the study of transitions across early education. Education and Treatment of Children, 13, 298-315.
Carta, J. J., Greenwood, C. R., \& Atwater, J. (2010, October). Tier 1 instruction in the early education classrooms: Implications for response to intervention. Kansas City: Center for Response to Intervention in Early Childhood, University of Kansas. Retrieved from http://www.crtiec.org/rti_summit/2010/08-carta-greenwoodatwater.shtml

Carta, J. J., Greenwood, C. R., Luze, G. J., Cline, G., \& Kuntz, S. (2004). Developing a general outcome measure of growth in social skills for infants and toddlers. Journal of Early Intervention, 26(2), 91-114.

Carta, J. J., Greenwood, C. R., \& Robinson, S. (1987). Application of an eco-behavioral approach to the evaluation of early intervention programs. In R. Prinz (Ed.), Advances in the behavioral assessment of children and families (Vol. 3, pp. 123-155). Greenwich, CT: JAI Press.

Carta, J. J., Greenwood, C. R., Walker, D., \& Buzhardt, J. (2010). Using IGDIs: Monitoring progress and improving intervention results for infants and young children. Baltimore: Brookes.

Carta, J. J., Sainato, D. M., \& Greenwood, C. R. (1988). Advances in the ecological assessment of classroom instruction for young children with handicaps. In S. L. Odom \& M. B. Karnes (Eds.), Research perspectives in early childhood special education (pp. 217-239). Baltimore: Brookes.

Carta, J. J., Schwartz, I., Atwater, J. B., \& McConnell, S. R. (1991). Developmentally appropriate practice? Appraising its usefulness for young children with disabilities. Topics in Early Childhood Special Education, 11, 11-20.

Center for Response to Intervention in Early Childhood (CRTIEC). (2009). Work scope of the Center for Response to Intervention in Early Childhood (CRTIEC). In M. R. Coleman, F. P. Roth, \& T. West (Eds.), Roadmap to Pre-K RTI. New York: National Center for Learning Disabilities. Retrieved from http://www.ncld. org/

Chard, D. J., \& Kameenui, E. J. (2000). Struggling first-grade readers: The frequency and progress of their reading. Journal of Special Education, 34(1), 28-38.

Coleman, M. R., Roth, F. P., \& West, T. (2009). Roadmap to pre-K RTI: Applying response to intervention. New York City: National Center for Learning Disabilities, Inc. Retrived from http://www.rtinetwork.org/images/roadmaptoprekrti.pdf

Conyers, L. M., Reynolds, A. J., \& Ou, S. (2003). The effect of early childhood intervention and subsequent special education services: Findings from the chicago child-parent centers. Educational Evaluation and Policy Analysis, 25(1), 75-95.

Council for Exceptional Children (CEC). (2007). CEC's position on response to intervention (RTI): The unique role of special education and special educators. Arlington, VA: Author.

Craig-Unkefer, L. A., \& Kaiser, A. P. (2002). Improving the social communication skills of at-risk preschool children in a play context. Topics in Early Childhood Special Education, 22, 3-13.

Division of Early Childhood (DEC). (2007). Promoting positive outcomes for children with disabilities: Recommendations for curriculum, assessment, and program evaluation. Missoula, MT: Author.

Emergent and Early Literacy Workshop. (2000, September). Current Status and Research Directions. Retrieved from http://www.nichd. nih.gov/crmc/cdb/r_house.htm

Fletcher, J. M., \& Vaughn., S. (2009). Response to intervention: Preventing and remediating academic difficulties. Child Development Perspectives 3(1), 30-37. 
Fox, L., Carta, J. J., Strain, P., Dunlap, G., \& Hemmeter, M. L. (2009). Response to Intervention and the Pyramid Model. Retrieved from http://www.challengingbehavior.org/do/resources/documents/rti_ pyramid_web.pdf

Fox, L., Carta, J. J., Strain, P. S., Dunlap, G., \& Hemmeter, M. L. (2010). Response to intervention and the Pyramid Model. Infants and Young Children, 23(1), 3-13.

Fuchs, L. S., \& Fuchs, D. (2007). The role of assessment in the threetier approach to reading instruction. In D. Haager, J. Klingner \& S. Vaughn (Eds.), Evidence-based reading practices for response to intervention (pp. 29-44). Baltimore: Brookes.

Gersten, R., Compton, D., Connor, C. M., Dimino, J., Santoro, L., Linan-Thompson, S. S., \& Tilly, W. D. (2008). Assisting students struggling with reading: Response to Intervention and multi-tier intervention for reading in the primary grades. A practice guide. (NCEE 2009-4045). Washington, DC: National Center for Education Evaluation and Regional Assistance, Institute of Education Sciences, US Department of Education. Retrieved from http://www.crtiec.org/RTI/documents/rti_reading_pg_021809. pdf

Gertner, B. L., Rice, M. L., \& Hadley, P. A. (1994). Influence of communicative competence of peer preferences a preschool classroom. Journal of Speech and Hearing Research, 37, 913-923.

Gilliam, W. S. (2006). Prekindergartners left behind: Expulsion rates in state prekindergarten systems. New Haven, CT: Yale University Child Study Center. Retrived from http://www.fcd-us.org/PDFs/ NationalPreKExpulsionPaper03.02_new.pdf

Girolametto, L., Weitzman, E., \& Greenberg, J. (2004). The effects of verbal support strategies on small group peer interactions. Language, Speech, and Hearing Services in the Schools, 35, 256-270.

Goldstein, H., \& Kaminski, R. (2010). Research conducted by CRTIEC on Tier 2 and Tier 3 interventions. Kansas City, KS: Center for Response to Intervention in Early Childhood, University of Kansas. Retrieved from http://www.crtiec.org/rti_summit/2010/ 19-goldstein-kaminski.shtml

Greenwood, C. R. (2008, July). Scaling up the use of evidence-based practices: What will it take to improve the outcomes of young children with disabilities? Paper presented at the 2008 OSEP Project Director's Conference, Washington, DC.

Greenwood, C. R. (2009). Foreward. In M. R. Coleman, F. P. Roth, \& T. West (Eds.), Roadmap to Pre-K RTI. National Center for Learning Disabilities. Retrieved from http://www.ncld.org/

Greenwood, C. R., Carta, J. J., Baggett, K., Buzhardt, J., Walker, D., \& Terry, B. (2008). Best practices in integrating progress monitoring and response-to-intervention concepts into early childhood systems. In A. Thomas, J. Grimes, \& J. Gruba (Eds.), Best practices in school psychology V (pp. 535-548). Washington, DC: National Association of School Psychology.

Greenwood, C. R., Carta, J. J., Walker, D., Hughes, K., \& Weathers, M. (2006). Preliminary investigations of the application of the Early Communication Indicator (ECI) for infants and toddlers. Journal of Early Intervention, 28(3), 178-196.

Greenwood, C. R., Kratchowill, T., \& Clements, M. (2008). Schoolwide prevention models: Lessons learned in elementary schools. New York: Guilford.

Greenwood, C. R., Luze, G. J., Cline, G., Kuntz, S., \& Leitschuh, C. (2002). Developing a general outcome measure of growth in movement for infants and toddlers. Topics in Early Childhood Special Education, 22(3), 143-157.
Greenwood, C. R., Walker, D., Carta, J. J., \& Higgins, S. (2006). Developing a general outcome measure of growth in the cognitive abilities of children 1 to 4 years old: The Early Problem-Solving Indicator. School Psychology Review, 35(4), 535-551.

Guralnick, M. J., Connor, R. T., Hammond, M. A., Gottman, J. M., \& Kinnish, K. (1996). The peer relations of preschool children with communication disorders. Child Development, 67, 471-489.

Head Start for School Readiness Act (2007).

Heckman, J. J. (2000). Invest in the very young. Chicago: Ounce of Prevention and the University of Chicago. Retrieved from http:// www.ounceofprevention.org/downloads/publications/Heckman.pdf

Heckman, J. (2006). Skill formation and the economics of investing in disadvantaged children. Science, 30, 1900-1902.

Hemmeter, M. L., Ostrosky, M., \& Fox, L. (2006). Social and emotional foundations for early learning: A conceptual model for intervention. School Psychology Review, 35, 583-601.

Howes, C., Burchinal, M., Pianta, R., Bryant, D., Early, D., Clifford, R., et al. (2008). Ready to learn? Children's pre-academic achievement in pre-kindergarten programs. Early Childhood Research Quarterly, 23, 27-50.

Huffman, L. C., Mehlinger, S. L., \& Kerivan, A. S. (2000). Risk factors for academic and behavioral problems at the beginning of school. Palo Alto, CA: Stanford University School of Medicine, Department of Pediatrics and The Children's Health Council.

Hunter, A., \& Hemmeter, M. L. (2009). The Center on the Social and Emotional Foundations for Early Learning: Addressing challenging behaviors in infants and toddlers. Zero to Three, 29(3), 5-12.

Individuals with Disabilities Education Improvement Act, 20 U.S.C., § 1400 et seq. (2004).

Juel, C. (2006). The impact of early school experiences on initial reading. In D. K. Dickinson \& S. B. Neuman (Eds.), Handbook of Early Literacy Research (Vol. 2, pp. 410-426). New York: Guilford Press.

Justice, L. M., \& Kaderavek, J. N. (2004). Embedded-explicit emergent literacy intervention I: Background and description of approach. Language, Speech, and Hearing Services in Schools, 35, 201-211.

Kaminski, R., \& Carta, J. J. (2010, October). Preschool Curriculum Checklist (PCC). Kansas City: Center for Response to Intervention in Early Childhood, University of Kansas.

Kaminski, R., Cummings, K. D., Powell-Smith, K. A., \& Good, R. H. (2008). Best practices in using Dynamic Indicators of Basic Early Literacy Skills for formative assessment and evaluation. In A. Thomas \& J. Grimes (Eds.), Best practices in school psychology $V$ (Vol. 4, pp. 1181-1204). Washington, DC: National Association of School Psychologist.

Kamps, D., Greenwood, C. R., Arreaga-Mayer, C., Abbott, M., \& Utley, C. (2002). Center for early intervention in reading and behavior to improve the performance of young children. Kansas City: Juniper Gardens Children's Project, University of Kansas.

Kouri, T. (2005). Lexical training through modeling and elicitation procedures with late talkers who have specific language impairment and developmental delays. Journal of Speech, Language and Hearing Research, 48, 157-171.

Kratchowill, T., Clements, M., \& Kalymon, K. M. (2007). Response to intervention: Conceptual and methodological issues in implementation. In S. R. Jimerson, M. K. Burns, \& A. VanDerHeyden (Eds.), The handbook of response to intervention: The science and practice of assessment and intervention (pp. 25-52). New York: Springer. 
Ladd, G. W., Kochenderfer, B. J., \& Coleman, C. C. (1996). Friendship quality as a predictor of young children's early school adjustment. Child Development, 67, 1103-1118.

Lane, K. L., O'Shaughnessy, T. E., Lambros, K. M., Gresham, F. M., \& Bebbe-Frankenberger, M. E. (2001). The efficacy of phonological awareness training with first-grade students who have behavior problems and reading difficulties. Journal of Emotional and Behavioral Disorders, 92, 19-23.

Lesko, J., Houle, G., \& Tschantz, J. (2010, October). State and federal policies supporting multi-tiered interventions in early education settings. Kansas City: Center for Response to Intervention in Early Childhood, University of Kansas. Retrieved from http://www.crt iec.org/rti_summit/2010/18-lesko-houle-tschantz.shtml

Linas, M. W., Carta, J. J., \& Greenwood, C. R. (2010, June). Taking a Snapshot of Early Childhood Response to Intervention Across the United States: 2009 and 2010. Washington DC: Head Start Research Conference.

Linas, M. W., Greenwood, C. R., \& Carta, J. J. (2009, June). Taking a snapshot of early childhood response to intervention across the states. Paper presented at the Fourth Annual IES Research Conference, Washington, DC.

Lonigan, C. J., Anthony, J. L., Bloomfield, B. G., Dyer, S. M., \& Samwel, C. S. (1999). Effects of two preschool shared reading interventions on the emergent literacy skills of children from low income families. Journal of Early Intervention, 22, 306-322.

Lonigan, C. J., Bloomfield, B. G., Anthony, J. L., Bacon, K., D., Phillips, B. M., \& Samwel, C. S. (1999). Relations among emergent literacy skills, behavior problems, and social competence in preschool children from low- and middle-income backgrounds. Topics in Early Childhood Special Education, 19, 40-53.

Marston, D. (2005). Tiers of intervention in responsiveness to intervention: Prevention outcomes and learning disabilities identification patterns. Journal of Learning Disabilities, 38, 539-544.

Mashburn, A. (2008). Evidence for creating, expanding, designing, and improving high-quality preschool programs. In L. M. Justice \& C. Vukelich (Eds.), Achieving excellence in preschool literacy instruction (pp. 5-24). New York: Guilford.

McConnell, S. R. (2000). Assessment in early intervention and early childhood special education: Building on the past to project into the future. Topics in Early Childhood Special Education, 20, 43-48.

McConnell, S. R., \& Missall, K. N. (2008). Best practices in monitoring progress for preschool children. In A. Thomas \& J. Grimes (Eds.), Best practices in school psychology (5th ed., pp. 561-573). Washington, DC: National Association of School Psychologists.

McIntosh, K., Horner, R. H., Chard, D., Boland, J. B., \& Good, R. H. (2006). The use of reading and behavior screening measures to predict nonresponse to school-wide behavior suppot: A longitudinal analysis. School Psychology Review, 35(2), 275-291.

Missal, K. N., \& McConnell, S. (2010). Early literacy and language IGDIs for preschool children. In J. J. Carta, C. R. Greenwood, D. Walker \& J. Buzhardt (Eds.), Using IGDIs: Monitoring progress and improving intervention results for infants and young children (pp. 181-201). Baltimore: Brookes.

Moats, L. (1999). Teaching reading is rocket science: What expert teachers of reading should know and be able to do. Washington, DC: American Federation of Teachers.

National Association for the Education of Young Children (NAEYC). (2011). Developmentally appropriate practice and intentionality: Big ideas. Washington, DC: Author. Retrieved from http://www.
naeyc.org/files/naeyc/file/ecprofessional/DAP\%20and\%20Inte $\mathrm{n}$ tionality\%20Big\%20Ideas.pdf

National Association of State Special Education Directors. (2008). Response to Intervention: Blueprints for Implementation. Alexandria, VA: Author.

National Reading Panel. (2000). Teaching children to read: An evidence-based assessment of the scientific research literature on reading and its implications for reading instruction. Washington, DC: National Institute of Child Health and Human Development.

National Research Council. (2008). Early childhood assessment: Why, What, and How. Washington, DC: Committee on Developmental Outcomes and Assessment for Young Children, The National Academies Press.

No Child Left Behind Act of 2001, U.S.C $\$ 6319$ (2001).

Nylander, D. (2009, October). Navigating through RTI with a compass and a lifeboat. Early Childhood RTI Summitt. Retrieved from http://www.crtiec.org/rti_summit/documents/NylanderNavigatingthroughRTIwithaCompass-NMSummitt10-09.pdf

Posney, A. (2010). OSEP policy letter regarding RTI in Head Start. Washington DC: Office of Special Education and Rehabilitation Services, US Department of Education. Retrieved from http://nec tac.org/ pdfs/idea/letters/Brekken-RTIHeadStart-6-2-10.pdf

Priest, J. S., McConnell, S. R., Walker, D., Carta, J. J., Kaminski, R., McEvoy, M. A., ... Shinn, M. R. (2001). General growth outcomes for children: Developing a foundation for continuous progress measurement. Journal of Early Intervention, 24(3), 163-180.

Ridley, S. M., McWilliam, R. A., \& Oates, C. S. (2000a). Observed engagement as an indicator of child care program quality. Early Education and Development, 11(2), 133-146.

Ridley, S. M., McWilliam, R. A., \& Oates, C. S. (2000b). Observing children at play: Using engagement to evaluate activities and the classroom environment. Children and Families, 14(3), 36-38.

Russell, J., McCoy, A., Pistorino, C., Wilkinson, A., Burghardt, J., Clark, M., . . S Swank, P. (2007). National Evaluation of Early Reading First: Final Report. US Department of Education, Institute of Education Sciences. Washington, DC: US Government Printing Office. Retrieved from http://ies.ed.gov/ncee/pdf/2007 4007.pdf

Sainato, D. M., \& Carta, J. J. (1992). Classroom influences on the development of social competence young children with disabilities. In S. L. Odom, S. R. McConnell, \& M. A. McEvoy (Eds.), Social competence of young children with disabilities: Issues and strategies for intervention (pp. 93-109). Baltimore: Brookes.

Sameroff, A. J., \& Fiese, B. H. (1990). Transactional regulation and early intervention. In S. J. Meisels \& J. P. Shonkoff (Eds.), Handbook of early childhood intervention (pp. 119-149). New York: Cambridge University Press.

Sandall, S. R., Schwartz, I. S., Joseph, G. E., Chou, H. Y., Horn, E., Lieber, J., . . . Wolery, R. (2002). Building blocks for teaching preschoolers with special needs. Baltimore: Brookes.

Scarborough, H. S. (1998). Early identification of children at risk for reading difficulties: Phonological awareness and some other promising predictors. In B. K. Shapiro, P. J. Accardo \& A. J. Capute (Eds.), Specific reading disability: A view of the spectrum (pp. 75-199). Timonium, MD: York Press.

Shinn, M. R. (2008). Best practices in using curriculum-based measurement in a problem-solving model. In A. Thomas \& A. Grimes (Eds.), Best Practices in School Psychology V (pp. 243-262). Washington, DC: National Association of School Psychologists. 
Shinn, M. R., \& Walker, H. M. (Eds.). (2010). Interventions for achievement and behavior problems in a three-tier model including RTI. Washington, DC: National Association of School Psychologists.

Shonkoff, J. P., \& Phillips, D. A. (2000). From neurons to neighborhoods: The science of early childhood development. Washington, DC: National Academy Press.

Snyder, P. A., Wixson, C. S., Talapatra, D., \& Roach, A. T. (2008). Assessment in early childhood: Instruction-focused strategies to support response-to-intervention frameworks. Assessment for Effective Intervention, 34(1), 25-34.

Thomas, A., \& Grimes, A. (Eds.). (2008). Best practices in school psychology V. Washington, DC: National Association of School Psychologists.

Torgesen, J. K. (1998). Catch them before they fall: Identification and assessment to prevent reading failure in young children. American Educator, 22, 32-39.

Torgesen, J. K. (2002). The prevention of reading difficulties. Journal of School Psychology, 40, 7-26.

Torgesen, J. K., Wagner, R. K., Rashotte, C. A., Rose, E., Lindamood, P., Conway, T., \& Garvan, C. (1999). Preventing reading failure in young children with phonological processing disabilities: Group and individual responses to instruction. Journal of Educational Psychology, 91, 579-593.

Treiman, R., Tincoff, R., \& Richmond-Welty, E. D. (1997). Beyond zebra: Preschoolers' knowledge about letters. Applied Psycholinguistics, 18, 391-409.

Tunmer, W. E., Herriman, M. L., \& Nesdale, A. R. (1988). Metalinguistic abilities and beginning reading. Reading Research Quarterly, 23(2), 134-158.

US Department of Education (USDE). (2006). FY 2007 Program Performance Plan. Retrieved from http://www.ed.gov/about/reports/ annual/2007plan/program.html

VanDerHeyden, A. M., \& Snyder, P. (2006). Integrating frameworks from early childhood intervention and school psychology to accelerate growth for all yound children. School Psychology Review, 35(4), 519-534.

Vaughn, S., \& Chard, D. (2006). Three-tier intervention research studies: Descriptions from two related projects. Perspectives, The International Dyslexia Foundation. Winter, 29-34.

Wackerle-Holman, A., \& Bradfield, T. (2010, October). Developing a new set of early literacy and language IGDIs. Kansas City, KS: Center for Response to Intervention in Early Childhood, University of Kansas. Retrieved from http://www.crtiec.org/rti_summit/2010/12-wackerlehollman-bradfield.shtml

Wagner, R. K., Torgesen, J. K., Rashotte, C. A., Hecht, S. A., Barker, T. A., Burgess, S. R., et al. (1997). Changing relations between phonological processing abilities and word-level reading as children develop from beginning to skilled readers: A 5-year longitudinal study. Developmental Psychology, 33, 468-478.

Walker, H. M., \& Shinn, M. R. (2010). Systematic, evidence-based approaches for promoting positve student outcomes within a multitier framework: Moving from efficacy to effectiveness. In M. R. Shinn \& H. M. Walker (Eds.), Interventions for achievement and behavior problems in a three-tier model including RTI (pp. 1-26). Washington, DC: National Association of School Psychologists.

Webster-Stratton, C. (1997). Early intervention for families of preschool children with conduct problems. In M. Guralnick (Ed.),
The effectiveness of early intervention (pp. 429-453). Baltimore: Brookes.

Whitehurst, G. J., \& Lonigan, C. J. (1998). Child development and emergent literacy. Child Development, 69, 848-872.

Whitehurst, G. J., \& Lonigan, C. J. (2001). Emergent literacy: Development from prereaders to readers. In S. B. Neuman \& D. K. Dickinson (Eds.), Handbook of early literacy research (pp. 1129). New York: Guilford Press.

Zill, N., \& Resnick, G. (2006). Emergent literacy of low-income children in Head Start: Relationships with child and family characteristics, program factors, and classroom quailty. In D. K. Dickenson \& S. B. Neuman (Eds.), Handbook of early literacy research (Vol. 2, pp. 347-371). New York: Guilford.

Ziolkowski, R. A., \& Goldstein, H. (2008). Effects of embedded phonological awareness intervention during repeated book reading on preschool children with language delays. Journal of Early Intervention, 31(1), 67-90.

\section{GLOSSARY}

Developmentally Appropriate Practice - As NAEYC defines it, developmentally appropriate practice (DAP) is a framework of principles and guidelines for best practice in the care and education of young children, birth through age 8 . It is grounded both in the research on how young children develop and learn and in what is known about education effectiveness. The principles and guidelines outline practice that promotes young children's optimal learning and development. The DAP framework is described in detail in NAEYC's Position Statement on Developmentally Appropriate Practice (PDF) released in 2009.

Differentiated Instruction - Differentiated instruction refers to the recognition that because children vary in life experiences, background knowledge, language, readiness, and preferences in learning that different educational experiences are needed to support students' successful learning. It means starting to teach where the students are and modifying instruction as learning indicates such modification is necessary. It is opposite of the view that one size instruction fits all students and is uniformly effective with all students.

Intentional Teaching - This is a precept in early childhood that values adult-guided experiences as an instrumental factor in what academic and developmental concepts children learn. It is opposed to child-guided classroom experiences, also highly valued factors in early childhood programs, where children are free to learn from their own experiences. Intentional teaching occurs when teachers create experiences where they present information, model skills, and guide the learning using instructional strategies towards a specific academic goal. 


\section{ONLINE RESOURCES FOR EC RTI}

\section{Center for Response to Intervention in Early Childhood}

(CRTIEC) is a research and development center funded by the National Special Education Research Center, Institute for Education Sciences to develop Tier 2, Tier 3 interventions, and progress monitoring measures for preschool language and early literacy. http://www.crtiec.org/

Annual EC RTI Summit: http://www.crtiec.org/RTI_sum $\mathrm{mit} / 2010 /$

CRTIEC's Preschool RTI network: http://www.crtiec.org/ aboutcrtiec/preschoolRTI.shtml

RTI Pre-K Action Network "The RTI Action Network is dedicated to the effective implementation of Response to Intervention (RTI) in school districts nationwide. Our goal is to guide educators and families in the large-scale implementation of RTI so that each child has access to quality instruction and that struggling students-including those with learning disabilities - are identified early and receive the necessary supports to be successful. The RTI Action Network is a program of the National Center for Learning Disabilities, funded by the Cisco Foundation and in partnership with the nation's leading education associations and top RTI experts." http://www.rtinetwork.org/pre-k

Recognition and Response provides educators with information and resources to help early educators address the needs of young children (3- to 5-year-olds) who show signs that they may not be learning in an expected manner, even before they begin kindergarten. http://www.recognitionandresponse.org/content/view/84/95/

The Recognition and Response model is now featured in the National Center for Learning Disabilities' Early Learning
\& Literacy Newsletter. http://www.getreadytoread.org/inde x.php?option=com_content\&task=view \&id=14\&Item id=33

The Center on the Social and Emotional Foundations for Early Learning (CSEFEL) is "focused on promoting the social emotional development and school readiness of young children birth to age 5 . CSEFEL is a national resource center funded by the Office of Head Start and Child Care Bureau for disseminating research and evidence-based practices to early childhood programs across the country." http://csefel.vanderbilt.edu/

Technical Assistance Center for Social and Emotional Intervention (TACSEI) is funded by the US Department of Education, Office of Special Education Programs. "TACSEI takes the research that shows which practices improve the social-emotional outcomes for young children with, or at risk for, delays or disabilities and creates FREE products and resources to help decision-makers, caregivers, and service providers apply these best practices in the work they do every day. Most of these free products are available right here on our website for you to view, download and use." http://www.challengingbehavior.org/do/pyramid_model.htm

Preparation of this manuscript was supported by grant \#R324C080011 from the Institute of Education Sciences, US Department of Education. The opinions expressed in this article are those of the authors and the granting agency. We acknowledge the contribution of our CRTIEC colleagues Jane Atwater, Howard Goldstein Annie Hommel, Naomi Schneider, Scott McConnell, Kristen Missall, Beth Spencer, Alisha Wackerle-Hollman, and a host of dedicated research assistants at University of Kansas, University of Minnesota, the Ohio State University, and the Dynamic Measurement Group. 


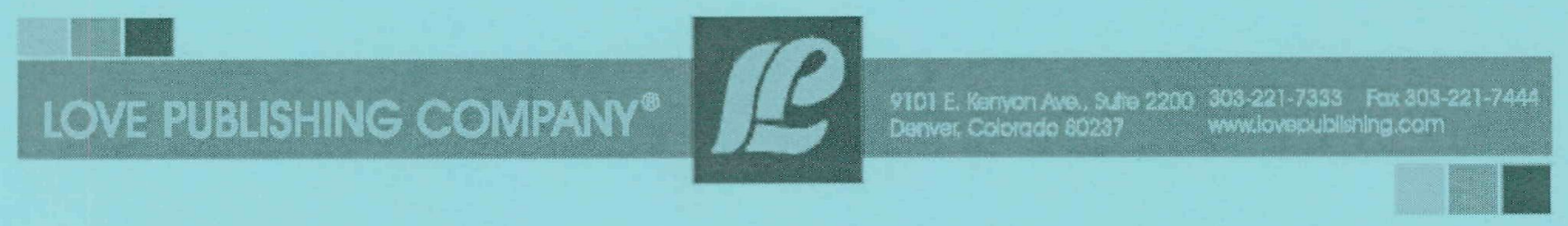

\title{
Language Instruction for Students with Disabilities
} Fourth edition

\author{
Edward A. Polloway, Lynda Miller, and Tom E. C. Smith
}

This textbook provides comprehensive coverage of communication and language development, and instruction in both oral language and language arts for students with special needs. The new fourth edition has been revised to reflect current research across the specific domains covered within the language area. The book is intended to be used as a text for coursework in teacher education training programs, with particular emphasis on classes related to language acquisition, language arts instruction, and curriculum and methods.

This edition includes major updates of the text with particular emphasis placed throughout the book on evidence-based practices. The authors collectively have over 90 years of experience working in the fields of learning disabilities; intellectual disabilities; and communication, speech, and language development.

\section{Special Features}

1. The book includes a strong focus on communication and language development across developmental levels. The first two chapters explore in depth language, speech, and communication and then analyze key developmental milestones related to communication, speech, and language development. In addition, extensive attention is given to considerations related to cultural and linguistic diversity.

2. The second section of the book provides an extensive discussion of oral language assessment and intervention. These areas are often underplayed or not addressed at all in textbooks focused on special education. In this domain, extensive attention is given to language considerations for preschool, school-age, and adolescent students, with particular emphasis on the social-pragmatic aspects of language that underlie many of the problems experienced by students with disabilities.

3. The third section of the book covers the areas that are traditionally referred to as language arts instruction. Two chapters address reading, three chapters address writing, and a final chapter provides special attention to language arts instruction for adolescent students with special needs.

\author{
Contents \\ 1. Introduction to Language, Speech, and Communication \\ 2. Language Development from Infancy through Adolescence \\ 3. Cultural Diversity and Language Differences \\ 4. Language Assessment and Instruction for Preschool Children \\ 5. Language Assessment and Instruction for School-Age Children \\ 6. Language Assessment and Instruction for Adolescents \\ 7. Reading Concepts and Assessment \\ 8. Reading Instruction \\ 9. Handwriting Instruction \\ 10. Spelling Assessment and Instruction \\ 11. Written Expression \\ 12. Adolescents and Language Disabilities
}

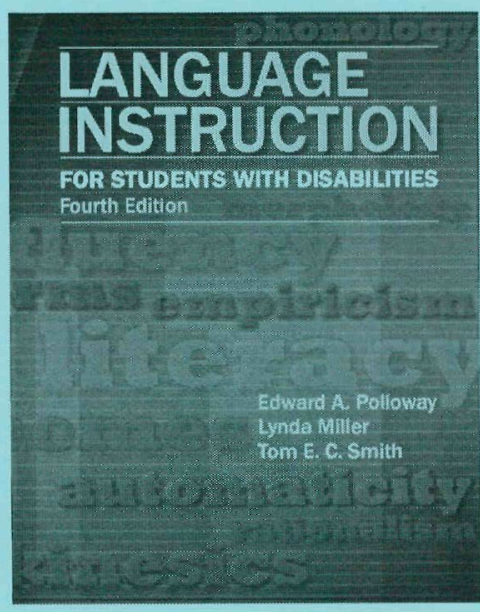

